\title{
A Synthesis of Data, Model-BASEd ANALySES, AND Refinements of Possible Management Scenarios FOR BISON AND ELK IN THE JACKSON VALLEY
}

\author{
LINDA C. ZEIGENFUSS $\uparrow$ U.S. GEOLOGICAL SURVEY $\uparrow$ FORT COLLINS \\ FRANCIS J. SINGER \ U.S. GEOLOGICAL SURVEY AND \\ COLORADO STATE UNIVERSITY $\uparrow$ FORT COLLINS \\ MICHAEL J. ROCK $\uparrow$ COLORADO STATE UNIVERSITY $\uparrow$ FORT COLLINS \\ MATT TOBLER $\uparrow$ U.S. GEOLOGICAL SURVEY $\uparrow$ FORT COLLINS $\uparrow$ CO
}

\section{$\uparrow \quad$ INTRODUCTION}

The elk and bison winter ranges in the Jackson Valley lie on a land complex consisting of Grand Teton NP (GTNP), National Elk Refuge (NER), town of Jackson, private ranches, and private housing developments. To reduce conflicts on these private lands, elk and bison are artificially fed alfalfa pellets at several feedgrounds located on the National Elk Refuge, the Gros Ventre Valley (Bridger-Teton $\mathrm{NF}$ ), and south of the town. The concentrations of elk may be altering vegetation communities, especially riparian willow, aspen, buffaloberry, and other woody shrubs near the feedgrounds. Managers are concerned about these possible alterations. Human developments, human alterations, artificial feeding and high incidence of brucellosis in elk and bison complicate management of free-ranging ungulates in Grand Teton NP and the Jackson Valley. Managers need additional information on predicted land use changes, feeding scenarios, and ungulate-disease relations in the Jackson Valley to guide their management decisions.

Elk numbers currently greatly exceed agency population goals by about $50 \%$. Managers are concerned about these high densities. In 1968, a population of 15-16 bison escaped from the park and was allowed to roam free in GTNP by local management agencies. In 1975, the bison began wintering on the NER and began using the elk feedgrounds as a food source. Since the discovery of the feedgrounds, nearly every individual in the herd has wintered on the refuge feedgrounds and, as a result, the population has increased dramatically to its current size of 573 bison (GTNP unpubl. data). The presence of a growing bison population in Jackson Hole has caused concern over the potential transmission of brucellosis from bison to domestic livestock. The large concentrations of both bison and elk on the NER feed grounds provide the opportunity for a higher rate of transmission and infection of the disease in the two species. The Brucella organism may be transmitted through ingestion of infected fetuses or fetal membranes, contact with the infected tissues, grazing on contaminated native forage, consuming contaminated feed or water, and possibly from contamination by feces left by infected animals (Crawford et al. 1990, T.J. Roffe, unpubl. data, Biological Resources Division, Bozeman, MT). These conditions are in abundance on the NER feedgrounds during the late winter and early spring where both bison and elk abortions occur. Elk are also a significant potential host for Brucella. Seropositive rates for elk wintering on the NER are $28 \%$ (39\% for adult females, Boyce 1989 as cited in Smith and Robbins 1994), but rates for free ranging elk in the Yellowstone ecosystem and elk not 
supplementally fed on feedgrounds elsewhere in Wyoming are closer to $2 \%$ (Thorne et al. 1991, Smith et al. 1994). The reduction or cessation of feeding at some, or all, of the feedgrounds has been proposed as a possible solution to the problem of heavy concentrations of ungulates and high incidence of disease. However, reduction of feeding will require reductions of elk and bison to some level of appropriate carrying capacity that are compatible with vegetation goals of the agencies. Winter distribution of the ungulates would also need to be compatible with private land ownership. Second homes and recreational homes are being built in the area at an exponential rate. Elk may habituate to humans, and preferentially use some irrigated and fertilized private food sources, such as pastures, lawns, and shrubbery. Continuing housing development on winter ranges may eventually result in a decline in occupiable winter range for ungulates. Managers need to know the rates and areas of current development, as well as predicted future development, and the locations where conflicts with ungulates will be most likely to occur.

Jackson Hole managers seek predictive maps of where all occupiable bison and elk habitat in the valley exists. We conducted multivariate analyses of the available information on bison and elk distributions and habitat selections. We also conducted a statistical test of the multiple habitat variables (snow depths, elevation, slope, aspect, cover vegetation, topographic position) and developed a gradient model to explain the habitat niches that bison and elk could occupy if they were not fed or were fed less. The statistical significance of the relative importance of these parameters is difficult to test, but best model approaches such as the Akaike's information criteria (AIC) are available to tell us which combination of habitat parameters is the best predictor while being the most economical in terms of number of variables involved in the model (Burnham and Anderson 1992). We then apply this best model to the entire valley, including all historic habitat, using GIS techniques to present managers with a map of both formerly occupiable habitat that is currently developed and all presently occupiable habitat.

About $2 / 3$ of the elk population in the Jackson Valley winters near feedgrounds, while about $1 / 3$ of the elk are free-ranging in areas away from the feedgrounds where they forage entirely on natural vegetation. Shrubs are more vulnerable to ungulate herbivory than are the (often) highly productive xeric and mesic grasslands in the valley. Managers may regulate numbers of ungulates based on shrub parameters and status in addition to herbaceous vegetation parameters. Managers are concerned over size reductions, and what visually appears to be over-browsing, of aspen, willow, and possibly buffaloberry and other shrubs, especially near the highest ungulate concentration areas in the valley. Identifying any thresholds of high elk densities, both on and off of feedgrounds, which may be negatively impacting woody shrubs could be critical in helping determine target elk densities or shrub consumption rates which are detrimental to plant community sustainability. Our experiences in Rocky Mountain NP indicated that good correlates were obtained between ungulate densities and willow growth parameters. We selected willows to sample because willows w ere not rare (correlates to growth parameters of rare species may not be linear, or even distinguishable, with elk densities) and because elk densities were apparently the most significant driving force (although other factors, such as fire, water tables, and climate might be important).

Assessment of potential management of wild ungulates in the Greater Teton area also requires information about current forage production in habitats used by wintering elk and bison as well as current levels of consumption, or offtake, of that production by wild ungulates. Studies to determine production and offtake on this winter range were initiated in 1996 and we have continued these measures into 2000. Sampling over several years can provide managers and modelers information on the range of responses in these variables that can be encountered over several seasons and with varying levels of precipitation.

Domestic livestock, especially cattle, grazing on allotments in GTNP and BTNF are a concern, both because of the risk of brucellosis transmission between domestic and native species, and because there is a possibility that livestock may competitively use forage which might otherwise be important to overwintering native ungulates. Options for decreased feeding of native ungulate species to alleviate brucellosis transmission may be limited by winter forage supply, which may be reduced by livestock grazing.

We also sampled any changes in plant species composition due to ungulates. Management of much of the world's grazing land is based primarily on changes in plant species composition (Milchunas and Lauenroth 1992). In particular, dominant individual species have been used as indicators of range condition under the increaserdecreaser-invader concept. Ungulates in national 
parks should not be allowed to exceed levels that impact these diversity values (Wagner et al. 1995). NPS (1988) policy states that the natural abundance and diversity of plants and animals should be maintained within the bounds of natural processes. Ungulates in pristine, natural ecosystems are known to alter plant species diversity in highly variable ways (McNaughton 1979; Pastor et al. 1993; Stohlgren et al. 1999). Research has demonstrated that ungulate grazing can alternatively decrease plant diversity (Rummell 1951; Chew 1982), result in no difference (Gough and Grace 1998; Stohlgren et al. 1999), or increase plant diversity (Grime 1973; Mueggler 1984). The effect of ungulates on plant diversity may be variable in natural systems depending on environmental conditions, evolutionary history of grazing, and predator limitation (Collins and Barber 1985; Stohlgren et al. 1999). The basic tenet by some researchers that there should be no measurable effects of ungulates on plant diversity (Wagner et al. 1995) has been questioned (McNaughton 1993, 1996). Management for maximum plant species diversity may, in some instances, include management for moderate or even high densities of ungulates. Thus, the grazing system and these major ecological relationships need to be well understood before managers can set goals for plant diversity.

This progress report is broken down into 5 sections detailing the progress on (I) winter habitat selection modeling for the $3 \mathrm{~m}$ ajor ungulate species wintering in the Jackson Valley, (II) willow growth correlates to browsing rates, (III) studies of herbaceous vegetation production and ungulate consumption rates on elk and bison winter range, (IV) wildlife distributions in relation to domestic livestock use of areas in the park, and (V) the effects of long-term exclusion of grazing on plant species diversity on elk winter range.

\section{Ungulate Winter Habitat Selection}

\section{$\uparrow \quad$ Methods}

Resource selection and preferred habitat characteristics of elk were determined using 786 locations from Wyoming Game and Fish Department (WGFD) aerial surveys (gathered during 1986-1997) and 865 radio telemetry locations from National Elk Refuge aerial surveys of approximately 168 collared individuals (gathered from 1990-1999). Moose locations $(n=622)$ were obtained from WGFD aerial surveys conducted in January-February 1999 and
February 2000. Bison locations $(n=519)$ were obtained from Grand Teton National Park from aerial surveys conducted from 1997-1999 in conjunction with radiotelemetry studies by Steve Cain and Carol Cunningham. Only locations c ollected between the winter months of November-April were used to determine habitat preferences and only those locations falling within the Jackson study area were used.

Information on elevation was obtained from USGS Digital Elevation Models (DEMs) for the area, and aspect and slope were derived from these maps using ARCVIEW geographic information system (GIS) software. Vegetation type was determined using a vegetation map compiled by Gary Wockner from vegetation maps from Grand Teton National Park, National Elk Refuge, and a coverage developed by Utah State University. These coverages had been merged and reclassified using the vegetation categories described in the landscape forage model documentation. Coverages of lakes and rivers were merged and distance to these water sources was determined. We attempted to isolate areas of bitterbrush based on maps provided by WGFD because these areas tend to be heavily used by moose in early and late winter and therefore might warrant designation as a separate vegetation type for moose habitat selection models. Unfortunately, the survey data available for moose were limited to January and February of 1999 and 2000 and no moose were observed in the bitterbrush areas during that time.

A map of areas around the NER and state feedgrounds in the Gros Ventre drainage where elk concentrate because they are fed hay or pelletized alfalfa in winter was provided by Steve Kilpatrick of WGFD. We also developed a map of areas within the study area that were open to elk hunting to determine whether this variable might contribute to selection of animal habitat.

Maps of snow water equivalents were developed for each day when radiolocation data on ungulates were collected. We used the snow model developed by Phil Farnes and modified by G. Wockner. Estimate of the snow water equivalent was determined for the site of each animal location using these snow maps.

We also compared habitats that had burned (in the last 5 years) or were unburned or burned $>5$ years ago. Maps of fires, both prescribed fires and wildfires, which had occurred within the study a rea during the last 70 years were provided by Bridger- 
Teton National Forest GIS personnel. This map was used to derive two variables, whether the area had burned during the last 70 years or not, and number of years since fires. Since many effects of fire on vegetation, such as forage abundance, forage quality, and species diversity, will rapidly diminish over time, we analyzed only those areas where fires had occurred within 5 years prior to the animal observation.

Based on initial analyses, agency feedback, and field observations, we decided to run two separate resource selection models, one for early winter (November and December) and one for late winter (January-April). Snow depths tend to accumulate more during the latter period. Snow water equivalent data was only available through water year 1999. Since we had a limited amount of moose observation data, half of which was collected in February 2000, we deemed it necessary to use this data in evaluating resource selection models. Therefore we examined SWE values for 6 weather stations on March 1, 2000 (the closest available date to our surveys) to determine SWE values for the dates of February 18-22, 2000. We then searched our precipitation data for the last 20 years to find the date with the most similar SWE values at all these weather stations. The selected date was February 15, 1995, and all SWE values were within 1" SWE of the station values on March 1, 2000. We then used the snow map for this day to determine SWE for all moose observations during the February 2000 survey.

In order to estimate selection by ungulates, we compared used habitat (the locations of ungulates) to a random set of locations. A number of locations equal to the number of observations for each species were randomly generated within the study area using ARCVIEW GIS. These random locations were for use in creating resource selection functions using logistic regression methods (Boyce and McDonald 1999). Each was randomly assigned an observation date from among the animal observation collection dates so that snow water equivalents could be generated. ARCVIEW geographic information system (GIS) software was used to integrate and derive habitat characteristics for all elk, moose, and bison locations and randomly generated points. All bison and elk locations, both random and actual, within the influence area of the feedgrounds as defined by WGFD personnel, were removed to reduce the influence of artificial feed on habitat selection. Since moose do not frequent feedgrounds, all moose observations were used.
Eight habitat variables were studied for selection by ungulates; vegetation type, distance to water (rivers and lakes), snow water equivalents, elevation, slope, aspect, hunting, and occurrence of a fire in the last five years. Locations which did not contain information for all habitat variables were removed from the data set. We also removed all locations within the influence of feedgrounds and outside the study area, which reduced the number of observed ungulate, and random locations that were used in the analysis (Table 1). We calculated a selection index (w) based on resource selection functions. A resource selection function is the proportion of used resource units of a type of those available and can be calculated by the equation:

$$
w_{i}=p_{i} / u_{i}
$$

where $p_{i}$ is the proportion of used resource units in category $i$, and $\mathrm{u}_{\mathrm{i}}$ is the proportion of resource units of category $i$ from all resource units available. This index can be standardized $\left(\mathrm{B}_{\mathrm{i}}\right)$ to allow more direct comparison between categories of an individual habitat variable. We determined whether observed habitat use was significantly different from that which would be expected based on the availability of the habitat throughout the study area using a loglikelihood chi-square test (Neu et al. 1974, Manly et al. 1993). We determined which habitats were preferred using $95 \%$ confidence intervals with a Bonferroni correction. This test was performed for all habitat variables except snow water equivalents, since these observations varied based on individual date of animal observations and we therefore could not calculate a standard proportion of the area in each category of snow water equivalent.

Logistic regression analyses were performed to determine the best model for predicting habitat selection for each species. We compared habitat variables from locations of ungulate use with the habitat variables for the set of random locations. The dichotomous response variable used in the logistic regression therefore was whether a location was observed or random. Eight habitat variables were involved in the choice of the best model; vegetation type, distance to water (rivers and lakes), snow water equivalents, elevation, slope, aspect, hunting, and time since fire. Akaike's information criteria (AIC) were used to determine the best model for predicting resource selection functions for each species. The resource selection probability function is the probability of selection of any particular grid cell in the study area. These probabilities were determined by using the best fitting logistic regression model in the following equation: 


$$
p_{i}=\frac{e^{\beta_{0}+\beta_{1} X_{1 i}+\ldots \beta_{k} X_{K i}}}{1+e^{\beta_{0}+\beta_{1} X_{1 i}+\ldots \beta_{k} X_{K i}}}
$$

where $\exists_{0 \ldots} \exists_{1}$ are the parameter estimates in the logistic regression equation and $\mathrm{X}_{1 \mathrm{i}} \ldots \mathrm{X}_{K i}$ are the values of the habitat variables (van Manen and Pelton 1997; Boyce and McDonald 1999). This probability is a relative measure because it is determined through comparison with random locations and is based on a sample of each species locations at certain periods of time, but it provides an index to predict degree of potential selection by each species.

\section{RESULTS}

Use of all habitats tested were significantly different from expected use based on their availability, with the exception of use of burned areas by moose $(P \leq 0.05)$. Both elk and bison significantly preferred sagebrush, aspen, wetland, and agricultural fields. Elk also showed a preference for riparian forest and developed areas, while bison also preferred wet meadows. Elk tended to avoid flat aspects, preferring slopes facing southeast, south, and southwest. Bison, however, preferred the flat areas, as well as southwest, west, and northwest aspects. Elk preferred slopes of less than $15^{\circ}$ at elevations of $2000-2600 \mathrm{~m}$. Bison were much more selective in this regard, preferring slopes of $\leq 5^{\circ}$ at elevations of 2000-2200 m (Table 2). Bison appeared to be particularly restricted by snow water equivalents with over $80 \%$ of observations occurring in areas of 1-inch snow water equivalent or less. Elk seemed confined mainly to areas of $\leq 4$ inches of snow water equivalent, though both elk and bison are apparently forced to use areas with deeper snow late in the winter (Table 3). Elk showed a slight preference for unhunted areas in the early winter, and then greatly preferred fall-hunted areas in late winter following the end of the hunting season, but the elk hunting did not lead to avoidance of hunted areas by bison. Bison actually seemed to prefer areas open to elk hunting, but this may be an artifact of the fact that the sagebrush and agricultural habitats that bison favor in early winter are encompassed within the hunted area. Overall, elk avoided areas that had been burned within the last 5 years, though they showed a slightly higher use of burned areas in early winter. Bison showed a significant preference for these recently burned areas in early winter; nearly $30 \%$ of observations. However, by late winter bison use of burned areas had decreased to only $5 \%$ of observations, though this was still significantly greater than for unburned areas (Tables 2 and 3).
Moose most often selected areas of willow, riparian forest, wet meadow, and wetlands on flat, north, or south slopes of less than $5^{\circ}$ at elevations between 2000-2400 m (Table 2). Ninety-five percent of all observations were within $1 \mathrm{~km}$ of water (streams, rivers, or lakes). Moose were not as restricted by snow, with nearly $50 \%$ of moose observations in locations with 5-8 snow water equivalents. Moose were not observed using any areas during January and February that had been burned in the last 5 years. Moose preferred using areas where elk were hunted, h owever, this may be an artifact of the fact that much of the preferred vegetation cover for moose fell within areas where fall elk hunting occurs (Table 2).

The best model for predicting both early and late winter elk habitat selection was the full model which included SWE, distance to water, vegetation type, aspect, slope, elevation, whether the area was open to elk hunting at that time, and occurrence of a fire within the last 5 years. However, the parameter estimates were different for each part of winter and reflect the early vs. late winter preferences noted in (Table 3). Much of the study area is available to elk during early winter (Fig. 1), but during late winters, and particularly, during severe winters, few high preference areas of habitat were available; only $3.7 \%$ of the entire study area (Fig. 2). Most of this late winter potential habitat use area was restricted to the Gros Ventre drainage on the Bridger-Teton National Forest east of the Jackson Valley and the lower part of the Jackson Valley (Fig. 2).

The best models for predicting early and late winter bison habitat selection included SWE, vegetation type, slope, elevation, whether the area was open to elk hunting, and occurrence of a fire within the last 5 years, but the late winter model also included aspect (Figs. 3, 4). A larger portion of the study area $(\sim 5 \%)$ was of potential habitat use $(>50 \%)$ by bison, even in a severe winter (Fig. 4), but most of this area was restricted to the NER and between the NER and the Snake River, just north of the town of Jackson (Fig. 4). The early winter model identifies a large area of high probability of use ( $>50 \%)$ west of the Snake River and south of the Triangle $\mathrm{X}$ ranch which currently doesn't receive much use (based on observations). The part of this area that lies south of the park boundary likely would not receive much use, even under larger bison population sizes because of development and competing livestock use. However, the areas within the park could be considered as areas that might possibly receive more use by bison in the future. 
Moose habitat selection was best predicted using a model that included SWE, distance to water, vegetation type, elevation, and whether the area was open to elk hunting. We did not have enough data to develop early and late winter models, but we modeled dates in mild and severe winter to compare preference areas between these model runs (Fig 5, 6). Most areas of high preference were located along drainages, particularly of larger rivers and streams, and willow flats near lakeshores (Fig. 5). In more severe winters, greater snow depths limited potential habitat to areas along the Snake and Gros Ventre Rivers near the town of Jackson, a willow flat in the Buffalo Valley, and a wetland area of the NER near the feedgrounds (Fig. 6). Although moose do not currently use this area of the NER (based on the observations used here and discussions with NER staff), this may be due to the high concentrations of elk on the feedgrounds and the consequent reduction of willow available as forage (see following section) in this area. These are conditions that might change if feeding were eliminated on the refuge.

Overlap in areas of high probability of use by all three species was not great (Fig. 7), even during severe winter conditions. Of $10 \%$ of the study area that was high preference area for at least one of the species of ungulates, only $0.003 \%$ of the study area was highly preferred by all three species, and an additional $1.7 \%$ of the study area was predicted to have high potential for use by at least 2 ungulate species (Fig. 7). Management action might be targeted to most affect the areas where overlap between species is the least to reduce competition for forages between species.

In the near future, we plan to model habitat selection of bison and elk species in Yellowstone National Park for comparison with the Grand Teton herds. Prior to the reintroduction of wolves, elk were estimated to be at carrying capacity, and we plan to test whether the habitat selection functions differ when populations are at or near this ceiling. We suspect that at higher population levels, such as those observed in Yellowstone, elk and bison will be less selective in their choice of habitat and that overlap between species will be greater. This information could be used to model potential changes in habitat use by each of these species, and pinpoint potential areas of conflict with human and livestock use in the Jackson Valley. We also will subdivide the models into pre- and post-wolf occupation of the winter range to determine whether the present of wolves has altered habitat selection by all species.

\section{Willow Production, Consumption, and Correlation to Winter Ungulate Density}

\section{$\downarrow$ MeTHODS}

We sampled 1999 and 2000 production, 1999-2000 winter consumption, and 2000 summer consumption of willows in 15 willow sites located in four strata: high elk and low moose densities (South end of NER), medium elk and medium moose densities (Gros Ventre drainage near Upper Slide Lake and Cottonwood Creek), medium elk and high moose densities (North end of NER and GTNP areas near Triangle $\mathrm{X}$ and Wolff Ridge), and low elk and moose densities (Buffalo Valley and along the Rockefeller Parkway). These strata were determined using elk and moose survey data provided by WGFD. Sample sites were randomly generated in each strata using GIS. Four random sites were then chosen in each stratum. Only three sites were available in the high elk-low moose density strata and these were confined to the southern end of the NER. Additionally, two of these sites were burned during prescribed burning in May of 2000, making spring data collection difficult.

Three $9.3 \mathrm{~m}^{2}$ randomly selected circular plots were established at each study site. Data collected on each shrub in all plots included species; canopy diameters (widest and perpendicular to widest diameter); plant height; number of stems; and an estimate of percent of canopy dead. On every fourth individual of each shrub of each species a subsample of the number of browsed and unbrowsed leaders; diameters at twig base, tip, and point of browse; and leader lengths were also collected. Winter consumption was measured before leaf bud break in May, and summer use was measured in August. Percent leader use was determined using the equation:

$\%$ leaderuse $=\frac{a}{a+b}$

where $\mathrm{a}=$ number of browsed leaders and $\mathrm{b}=$ number of unbrowsed leaders. Average percent twig removed was determined using the method of Jensen and Urness (1981) and Pitt and Schwab (1990) following the formula:

$\%$ twiguse $=\frac{100\left(D_{p}-D_{t}\right)}{D_{b}-D_{t}}$

where $D_{p}=$ twig diameter at point of browsing, $D_{t}=$ 
diameter of a representative sample of twig tips, and $\mathrm{D}_{\mathrm{b}}=$ basal diameter of current year's twig growth. Total consumption was determined by multiplying $\%$ leader use by $\%$ twig use. For short, single stem, densely growing species, such as wolf willow (Salix wolfii), we measured all plants within $1 \mathrm{~m}^{2}$ plots, then determined the coverage of the circular plot which was contiguously covered by these species and estimated production for the entire plot based on the $1 \mathrm{~m}^{2}$ plot.

Annual production was determined following methods of Singer et al. (1994). Average twig weight was calculated from linear regression of dry weight (dependent variable) on twig length or green twig basal diameter. Ten to twenty twig samples were taken from all willow species as well as from shrubby cinquefoil, Potentilla fruticosa, (which was also quite common in most sites) at each site. Separate regression equations were developed for each species and each treatment. $\mathrm{R}^{2}$ values ranged from $0.63-0.93$. The biomass of each willow plant where twig measurements were taken was estimated by multiplying average twig weight $x$ average number of twigs per stem $\mathrm{x}$ number of stems per plant. Regression equations were then developed relating canopy area or volume to production for these plants. These regressions were used to estimate biomass for the remaining plants that had no twig measurements. These $r^{2}$ values ranged from 0.64 0.94. 1999 willow production was estimated in a similar manner from data collected during May 2000, but due to lack of species identification, pooled regression equations were developed across all willow species for each treatment. Leaves were included in the summer twig weight measurements and this, as well as differences in estimation methods, may account for large differences in annual shrub production. Willow species were divided into two height categories; those species which are naturally of short stature (< $1.5 \mathrm{~m}$ greatest height, $S$. wolfii, $S$. candida, $S$. farriae), and those which have the potential to grow greater than $1.5 \mathrm{~m}(S$. boothi, $S$. bebbiana, $S$. geyeriana, $S$. planifolia). We then pooled these "short" and "tall" species to test differences in average willow heights between strata.

We tested for differences in consumption and production levels between varying ungulate densities using general linear models procedures. Fisher's least significant difference test was used to test for specific comparisons between the various ungulate density categories. Due to the very different methods used to estimate production for 1999 and 2000 , we did not test for yearly differences in this variable, however we did test differences in canopy coverage. Statistical analyses were performed using SAS statistical analysis software ver. 8.0.

\section{RESULTS}

We identified seven species of willow throughout the study area, with the highest diversity of willow species occurring in the area of highest elk density on the south end of the NER, where burning had occurred. Other species found in the study area included Potentilla fruticosa, Betula glandulosa, Rosa spp., Ribes spp., and occasional Artemisia tridentata and $A$. cana.

Winter shrub consumption was significantly higher $(P=0.04)$ in the strata of high elk and low moose density (Fig. 8a); however, this high consumption did not appear to prevail into the early summer. Summer willow consumption rates over all strata were generally low (less than $2 \%$ on average) and did not differ significantly based on ungulate density strata. Annual shrub production in willow communities was significantly greater in sites with medium densities of both ungulate species (Fig. 8b) in $2000(P=0.04)$, but this difference was only significant between the medium ungulate densities strata and the high elk-low moose density strata in $1999(P=0.11)$. Annual production differences between 1999 and 2000 may indicate problems with our ability to predict 1999 production by measuring plants in spring 2000. We believe that an additional year of data collection planned for 2001 will assist with better estimating overall annual shrub production in these willow sites.

Willow heights were significantly greater $(P$ $=0.05)$ for tall stature willow species in areas with medium elk and medium moose densities (244.6 $\forall$ $36.5 \mathrm{~cm}$; $0 \forall \mathrm{se}$ ) than areas with high elk and low moose densities $(89.9 \forall 28.3)$ or low elk and low moose densities (146.6 $\forall$ 21.7). A verage height of tall stature species in the medium elk and high moose density strata were not different from any of the other strata $(165.8 \forall 39.9)$. No willows of the short stature species were found in areas with medium elk and high moose densities. However, amongst the other three strata, short stature willow species were significantly sh orter in s trata with high elk and low moose densities $(22.0 \forall 6.0 \mathrm{~cm})$, than low elk and low moose $(79.0 \forall 11.5)$ or medium elk and medium moose $(55.6 \forall 7.0)$ densities $(P=0.04)$. One of the most common species, Salix boothii, was significantly shorter $(P=0.0005)$ in areas with high ungulate densities (high elk-low moose, and medium 
elk-high moose), than areas with lower ungulate densities (Fig. 8c) and this species can reach heights of over $3 \mathrm{~m}$ in our study sites.

Total shrub cover was significantly lower in high elk-low moose density strata in both years $(P<$ 0.08 ), but similar in areas of medium and low elk densities, regardless of moose density (Fig. 9). Shrub cover did not differ significantly between any strata except medium elk-medium moose density where there was greater cover in $2000\left(0.98 \pm 0.05 \mathrm{~m}^{2}\right)$ compared to $1999\left(0.63 \pm 0.04 \mathrm{~m}^{2}, P=0.002\right)$.

Consumption rates were negatively correlated to shrub production in willow sites $(P=$ $0.04, r^{2}=0.28$ ), however, lower productivity in 2 sites with no evident consumption, was followed by increases in productivity at $3-12 \%$ consumption, then decreasing productivity at higher consumption levels (Fig. 10). This could be an indication of grazing optimization, where moderate levels of browsing lead to release of buds, stimulating increased plant productivity. Tests of second-order regression models, which would indicate grazing optimization, were close to significance $\left(P=0.105, \mathrm{r}^{2}=0.31\right)$. We hope that a second year of data collection will provide enough additional data to discern whether high levels of consumption are consistently related to downward trends in production, or whether production increases slightly with low level of consumption, up to some threshold, beyond which production decreases occur.

Willow production was negatively correlated $\left(P=0.0041, \mathrm{r}^{2}=0.54\right)$ with elk densities, however, elk densities tended to vary greatly between the high density strata $\left(83.6 \mathrm{elk} / \mathrm{km}^{2}\right)$ and medium density strata (no greater than $6.76 \mathrm{elk} / \mathrm{km}^{2}$ ), with no densities between these extremes. A second year of production data should help better discern any threshold relationships between elk density and declining production.

We will continue to work on developing regressions for twig-only biomass estimates, so that we can make better estimates of production for 1999 . Future work should also focus on better delineating elk densities near the study sites, perhaps by focusing on NER data (current density w ork is based on WGFD flights which lump the refuge into one density class).

\section{Winter range vegetation production and domestic livestock studies}

\section{$\uparrow \quad$ METHODS}

Annual herbaceous standing crop biomass was sampled by clipping within $0.25-\mathrm{m}^{2}$ circular quadrats inside and outside $1-\mathrm{m}^{2}$ movable grazing exclosures that had been randomly placed at the beginning of the growing season in July 1996-1998 and 2000. All graminoids, forbs, and sub-shrubs within the quadrat were clipped and sorted into dead and live portions to measure annual peak production. Vegetation was oven dried at $55^{\circ} \mathrm{C}$ for at least 48 hours and then dry weighed. Visual estimates of percentage (to nearest $5 \%$ ) bare ground, moss, lichen, cacti, and shrub cover were recorded for each plot.

Winter herbaceous consumption was determined in 1998 and 2000 by clipping in spring (prior to green-up), from inside and outside movable grazing exclosures placed at the end of the previous growing season. Cages were randomly replaced after the spring sampling to capture the early summer consumption that occurs during the time elk are migrating to summer ranges. Percent consumption was calculated using the following formula:

$\%$ consumption $=\frac{100 *\left(\mathrm{~B}_{\mathrm{i}}-\mathrm{B}_{0}\right)}{\mathrm{B}_{\mathrm{i}}}$

where $B_{i}=$ dry weight of biomass inside grazing cage, and $\mathrm{B}_{\mathrm{o}}=$ dry weight of biomass outside of grazing cage. Summer consumption data were collected late June-late July throughout the study area. We attempted to measure areas at lower elevations first and follow the peak of growing season as we moved up in elevation.

In the Uhl Hill-Cunningham area of domestic livestock allotments, we conducted more detailed studies to try to differentiate the consumption by the main wild ungulate species (moose, elk, bison, and pronghorn) and domestic livestock. We also sampled in strata used by wild ungulates only and we compared those to nearby paired strata used by livestock and wild ungulates. In areas used by livestock and wildlife, we sampled both irrigated and non-irrigated pastures. Production and summer consumption data in areas grazed by livestock were collected in late June, before the arrival of livestock and again in late September after livestock were removed. Evening ground distribution surveys were conducted on or near the pasturelands at about 1-week intervals from May-August. All groups of bison, elk, cattle, horses, and pronghorns observed were plotted on a map. T hese a ttendance surveys were used to apportion the relative consumption during the periods of livestock occupation of the areas (see Section IV). 


\section{RESULTS}

Winter herbaceous consumption was greatest in burned sagebrush and mixed shrub areas in winter 1997-98 (Fig. 11a), but in winter 1999-2000 sagebrush, mixed shrub, mixed grass, and sedge areas were used heavily ( $>50 \%$ consumption of annual biomass). The heavier use of grass dominated types in 1999-2000 may reflect the low snow in this year which made these types more a vailable. $V$ ariations in consumption level in types measured both winters indicate high variability from year to year which may be based on weather, or ungulate movements in response to increased wolf activity. An additional year of data collection in 2001 on winter consumption levels will better discern these use patterns. Summer consumption was generally low, however, it also showed great annual variability (Fig. 11b).

Early spring consumption by wildlife (before livestock grazing began) was not significantly different between irrigated and non-irrigated pastures or wildlife only vs. wildlife areas that had livestock grazing (Fig. 12). Early spring consumption was generally very low. Consumption rates in the wildlife only areas remained low throughout the summer. Consumption rates on wildlife only areas were significantly lower $(P=0.02)$ than areas grazed by livestock (Fig. 12). Areas of Kentucky bluegrass (Poa spp.) near Cunningham Cabin, which were naturally sub-irrigated but not actively irrigated, were grazed particularly heavily by both livestock and wildlife.

Total herbaceous production also showed some annual variability, though the lowest production numbers were observed in 2000 , which was a drought year (Fig. 13). Production values were similar between the years 1996-98, except for the two types (conifer and burned sage) which had fewer sites measured in $1996(n=1)$ vs. $1998(n=4)$. We have likely covered a wide range of the variability in production within the four years of our study. As expected, herbaceous production was greater $(P<$ 0.056 ) in irrigated pastures than in non-irrigated areas (whether livestock grazed or not), but irrigation effectively lengthened the growing season as well. Herbaceous production on irrigated plots was double that of non-irrigated plots in June, but triple nonirrigated by late September (Fig. 14), however, standing crop available for wildlife in the fall was greatly reduced by the presence of domestic livestock on both irrigated and non-irrigated pastures.

\section{Wildlife Observations in Relation to Presence of Domestic Livestock}

\section{METHODS}

Wild and domestic ungulates were surveyed in an area of Grand Teton National Park over the summer of 2000 to quantify the effects of domestic livestock on wild ungulates. We looked at the distribution and density of wild ungulates before and after cattle were put on to grazing allotments. Fourteen surveys were conducted from park roads and trails between May 31, 2000 and August 3, 2000 in the areas of the Elk Ranch, West Elk Ranch, Triangle X, Cunningham Cabin, and Moose Head Ranch. Morning surveys were conducted between 0500 and 0700 hours, evening surveys were conducted from 1900 to 2100 hours. Elk, bison, pronghorn antelope, mule deer, horse, and cattle groups were recorded and mapped. Total numbers of species on each survey were recorded (Table 4 and Fig. 15).

We tested to see if the number of elk, bison and pronghorn differed before and after cattle were introduced. We used the Wilcoxon test, a nonparametric statistic comparable to a t-test. The ttest was inappropriate in this case because of the small sample size and lack of normal distribution of the data. Forty-four groups consisting of 346 wild animals (elk, bison, pronghorn, mule deer) were observed on agricultural land. There were 219 total wild animal group observations including 1,813 animals.

\section{$\uparrow \quad$ Results}

Before the arrival of cattle onto the ranges, the average numbers of elk, bison and pronghorn seen per survey was $112.9,44.5$, and 5.8 respectively. After cattle were introduced, the averages dropped to $65.3,15.8$ and 5.3 respectively. The average number of cattle was 1011.3 (while cattle were present). The average number of horses observed before cattle were introduced was 22 , after cattle the average number of horses increased to 33.8. There was a statistically significant drop in elk $(P=0.05)$ and bison $(P=0.08)$ observed in these areas after cattle were put on the allotments. Pronghorn numbers did not change significantly $(P=0.40)$ before or after cattle. 
We calculated ungulate use of individual grazing allotments that had large cattle herds. A herd of 1000 cattle was moved between several allotments during the survey period. The average numbers of elk and bison seen per survey in each of these allotments before cattle grazed there were compared to numbers after the cattle herd grazed (Table 5). Elk and bison use dropped in every allotment after the 1000-head cattle herd grazed the pasture.

Density of wild ungulates was mapped before cattle were brought onto the rangelands (prior to June 26, 2000) and after (June 26 and later). The wild ungulates that remain shifted their positions slightly after the cattle appeared (Fig. 16). More of the wild ungulates were observed in the Uhl Hill allotment far away from domestic livestock use. Some of the wild ungulate activity that did occur near domestic use on Uhl Hill was before cattle were put on the Uhl Hill allotment, but after cattle appeared in the general area. The wild ungulate activity on the West Elk Ranch shifted from the southern portion of the allotment before the arrival of cattle, to the northern part after cattle were put on. Most of the domestic livestock use of the West Elk Ranch is in the southern portion. In the Lower CunninghamTriangle $\mathrm{X}$ area the wild ungulates use moved slightly to the west and away from domestic use.

We plan to continue a second summer of wildlife observations on these domestic livestock grazing allotments in 2001. These data will help us determine whether patterns seen during 2000 are consistent over a second season. Two important questions still need to be addressed. Does this avoidance of cattle result in any negative impact on the wild ungulates, or is forage adequate everywhere? Are wild ungulates using less desirable habitats after the cattle are released?

\section{Plant Species Diversity Responses to Long-term Exclusion of Grazing}

\section{$\uparrow$ METHODS}

We evaluated plant diversity and production responses to grazing with the Modified-Whittaker plot technique (Stohlgren et al. 1995). The ModifiedWhittaker plot estimates species richness (number of species) and abundance (percent of cover) data at multiple spatial scales by using $1 \mathrm{~m}^{2}, 10 \mathrm{~m}^{2}$, and 100 $\mathrm{m}^{2}$ subplots nested within a $1000 \mathrm{~m}^{2}$ plot (Figure 17). Tenth hectare plots were located inside and adjacent to the Davis Hill (Moran), Uhl Hill, and NER grazing exclosures. Plots with similar slopes, aspects, and characteristics were chosen within each replicate. Each $20 \mathrm{~m} \mathrm{X} 50 \mathrm{~m}$ plot was oriented with its long axis aligned down the fall line of the slope and located at least three meters from exclosure fences.

Analysis of Modified-Whittaker data yields several types of information about a site including: frequency, percent cover and average height for each species present; and frequency and percent cover by: origin (native or exotic), duration (annual, biennial, perennial), growth habit (forbs, graminoids, shrubs, succulents, trees, sub-trees), and by species with less than one percent average cover. The maximum and average cover by cryptobiotic crusts, and the six most dominant species by average percent cover were also summarized. The maximum and average percent cover by rock, soil, litter, standing dead wood, manure, down wood, and standing water were recorded for each plot. Percent cover and average height information were derived from field estimates made in the 10 numerical subplots only. Species present in the A, B, C, and $\mathrm{K}$ plots do not contribute to percent cover estimates (Figure 17). We estimated foliar cover, therefore, total cover may exceed $100 \%$.

We measured herbaceous plant production from five randomly located $0.25 \mathrm{~m}^{2}$ circular plots within each of the six Modified-Whittaker plots. Plants found within these circular plots were clipped to the ground, separated by species, oven-dried at $55^{\circ} \mathrm{C}$, and weighed. Plant species that could not be identified in the field were collected and identified at the Park herbarium. Plants that could not be identified at the species level were identified to genus or grouped as unknowns. All sampling was conducted in the first two weeks of June 2000 .

All data were organized for analysis in Microsoft Excel and analyzed in SysStat ${ }^{\circledR}$ (version 6.0). Jaccard's Coefficient (Krebs 1989) was used to compare species overlap $\left(1000 \mathrm{~m}^{2}\right.$ plot data) between exclosed plots and a djacent grazed plots. Ja ccard's Coefficient was calculated using the following equation:

$$
\mathrm{J}=\mathrm{A} /(\mathrm{A}+\mathrm{B}+\mathrm{C})
$$

where $\mathrm{A}=$ the total species found in both sites, $\mathrm{B}=$ species found in site 1 but not in site 2 , and $C=$ species found in site 2 but not in site 1. A comparison of two species lists resulting in a similarity coefficient of 1.0 indicates complete overlap, while a coefficient of 0.0 indicates no overlap.

The Shannon-Weaver (1962) diversity index was also used to measure the overall diversity of the plot. Higher index values indicate a more diverse 
community. Shannon's Index values were calculated with the following equation:

$$
H=-\sum_{k=1}^{s}\left(P_{k}\right) \ln \left(P_{k}\right)
$$

where $P_{k}=$ the proportion of total cover contributed by species $\mathrm{k}$, and $\mathrm{s}=$ the number of species found on a site.

Differences in Shannon's Diversity Index values $(\mathrm{H})$ were tested using non-parametric methods (Kruskal-Wallis test). Paired T-Tests were used to compare differences in the frequency $\left(1000 \mathrm{~m}^{2}\right.$ and $1 \mathrm{~m}^{2}$ plot data) and percent cover $\left(1 \mathrm{~m}^{2}\right.$ plot data) of species' origin, duration, and growth habit for the three exclosure sites. Analysis was conducted on the $1000 \mathrm{~m}^{2}$ plot frequency, $1 \mathrm{~m}^{2}$ plot frequency, and the $1 \mathrm{~m}^{2}$ plot average frequency data to identify any scale dependent differences. Paired T-Tests were also used to evaluate the differences in plant production at the species and growth form levels. Values for the five $0.25 \mathrm{~m}^{2}$ circular plots were averaged before comparing treatments within a site, $P<0.05$ was used to determine significance in all tests. A species level comparison was made by developing a comprehensive list of all plants found within the 0.25 $\mathrm{m}^{2}$ circular plots. This list was then applied to all circular plots and zeros were entered for absent species.

\section{RESULTS}

The species composition, frequency, and percent cover of grazed and ungrazed sites were very similar. These sites shared seven of the ten most abundant species. Common forage species (Agropyron spicatum, Purshia tridentata, Poa fendleriana) were found in greater abundance on ungrazed sites (Table 6). Jaccard's Coefficient indicated a high degree of species overlap for grazed and ungrazed plots in sites 1, 2 and 3, which had $75.4 \%, 84.3 \%$ and $75.0 \%$ overlap respectively. Stohlgren et al. (1997) found species lists at 26 longterm grazing exclosures and their adjacent grazed plots averaged $57.9 \pm 2.8 \%$ species overlap. Comparison of the Shannon's Index values for grazed plots at sites Davis Hill, NER, and Uhl Hill were $\mathrm{H}=$ 2.943, $\mathrm{H}=2.226$, and $\mathrm{H}=2.451$ respectively; Shannon's Index values for ungrazed plots at sites Davis Hill, NER, and Uhl Hill were $\mathrm{H}=2.396, \mathrm{H}=$ 2.119 , and $\mathrm{H}=2.393$ respectively. A Kruskal-Wallis test of Shannon's Index values also indicated similarity between grazed and ungrazed areas $(P=$ 0.275).
Analysis of Modified-Whittaker data indicated few differences between grazed and ungrazed plots. Grazed plots averaged $39 \pm 6.6(0 \pm$ SE) species $/ 1000 \mathrm{~m}^{2}$ while ungrazed plots averaged $35.3 \pm 3.7$ species $/ 1000 \mathrm{~m}^{2}(P=0.55)$. At the same scale, native species richness ranged from $23 \pm 1.8$ in grazed plots to $24 \pm 3.5$ in ungrazed plots $(P=0.77)$; exotic species richness ranged from $4.3 \pm 1.7$ in grazed plots to $5.3 \pm 1.2$ in ungrazed plots $(P=0.22)$. Native species cover $\left(1 \mathrm{~m}^{2}\right.$ plot data) averaged $62.7 \pm$ $15.6 \%$ in grazed plots and was $72.6 \pm 4.7 \%$ in ungrazed plots $(P=0.58)$.

Percent of exotic cover was $1.9 \%$ greater in grazed plots than ungrazed plots $(P=0.003)$, and ungrazed plots had $15.0 \%$ more cryptobiotic crust cover $(P=0.030)$. The amount of non-vegetative cover (rock, soil, litter, duff, manure and wood) was nearly significant, $17.2 \%$ higher in grazed areas $(P=$ 0.069). These differences were not replicated in species frequency measurements from the $1000 \mathrm{~m}^{2}$ or $1 \mathrm{~m}^{2}$ plots. No other significant differences between grazed and ungrazed plots were detected in the analysis of Modified-Whittaker data (Table 7).

Biomass estimates derived from the circular plots indicated the total biomass of grazed areas to be $43.1 \pm 10.9$ grams $/ \mathrm{m}^{2}$ while the total biomass in ungrazed plots was $34.1 \pm 12.4$ grams $/ \mathrm{m}^{2}$. The difference in the total biomass between grazed and ungrazed plots was nearly significant $(P=0.055)$, however, no significant differences were found in the forb, graminoid, or subshrub biomass of grazed and ungrazed plots (Table 8). No significant differences between grazed and ungrazed plots were found at the species level.

Future work will focus on measuring offtake levels at the grazed plots adjacent to each exclosure in an attempt to determine effects of local offtake levels on plant species diversity and production. A series of small movable grazing exclosures were placed at each exclosure site in late summer 2000 and will be sampled for winter consumption in late April 2001 and again in summer 2001. As part of a partner study on nitrogen dynamics, we hope to add additional exclosures, with varying levels of time since plot was last grazed, grazing intensity, and proximity to feedgrounds, which we will sample for production and species diversity during summer 2001 and 2002. The increase in the number of exclosures will increase our sample size and will give us a greater ability to discern whether plant production and diversity differences are evident in the absence of grazing. 


\section{ACKNOWLEDGEMENTS}

This project is funded by the Natural Resources Preservation Program and the National Park Service, Grand Teton National Park in cooperation with the Natural Resources Ecology Lab at Colorado State University. We appreciate the assistance of Robert Schiller and Steve Cain of Grand Teton National Park; Bruce S mith and Eric Cole of the National Elk Refuge, U.S. Fish and Wildlife Service; Steve Kilpatrick of Wyoming Game and Fish Department; Jim Ozenberger of Bridger-Teton National Forest; Gary Wockner and Tom Hobbs of Colorado State University, and Phil Farnes.

\section{$\uparrow$ Literature CITED}

Boyce, M. S. 1989. The Jackson elk herd: intensive wildlife management in America. Cambridge University Press, United Kingdom.

Boyce, M.S., and L.L. McDonald. 1999. Relating populations to habitats using resource selection functions. Trends in Ecology and Evolution 14:268-272.

Burnham, K. P., and D. R. Anderson. 1992. Databased selections of an appropriate biological model: The key to modern data analysis. Pages 16-30 in D. R. McCullough and R. H. Barrett, editors. Wildlife 2001: Populations. Elsevier Applied Science Publications, New York. 1163 pp.

Chew, R. M. 1982. Changes in herbaceous and suffrutescent perennials in grazed and ungrazed desertified grassland in southeastern Arizona. 1958-78. American Midland Naturalist 108:159-169.

Collins, S. L., and S. C. Barber. 1985. Effects of disturbance on diversity in mixed-grass prairie. Vegetatio 64:87-94.

Crawford, R.P., L.G. Adams, T.A. Ficht, J.W. Templeton, and J.D. Williams. 1990. Effect of stage of gestation on efficacy of Brucella abortus strain-19 vaccination in cattle. American Journal of Veterinary Research 52:1848-1851.
Gough, L., and J. B. Grace. 1998. Herbivore effects on plant species diversity at varying productivity levels. Ecology 79:1586-1594.

Grime, J. P. 1973. Control of species density in herbaceous vegetation. Journal of Environmental Management 1:151-167.

Jensen, C.H., and P.J. Urness. 1981. Establishing browse utilization from twig diameters. Journal of Range Management 34(2):113116.

Krebs, C.J. 1989. Ecological methodology. Harper and Row, New York. New York, USA.

Manly, B.F.J., L.L. McDonald, and D.L. Thomas. 1993. Resource selection by animals: Statistical design ad analysis for filed studies. Chapman and Hall.

McNaughton, S. J. 1979. Grazing as an optimization process: Grass-ungulate relationships in the Serengeti. American Naturalist 11:691-703.

McNaughton, S. J. 1993. Grasses and grazers, science and management. Ecological Applications 3:17-20.

McNaughton, S. J. 1996. Wildlife policies in U.S. national parks. Journal of Wildlife Management 60:685-687.

Milchunas, D. G., and W. K. Lauenroth. 1992. Quantitative effects of grazing on vegetation and soils over a global range of environments. Ecological Monographs 63:327-366.

Mueggler, W. F. 1984. Diversity of western rangelands. Pages 211-217 in J. L. Cooley and J. H. Cooley, editors. Natural Diversity in Forest Ecosystems Proceedings Workshop. University of Georgia, Athens.

National Park Service. 1988. Management policies. U.S. Government Printing Office, Washington, D.C.

Neu, C.W., R. Byers, and J.M. Peek. 1974. A technique for analysis of utilizationavailability data. Journal of Wildlife Management. 38:541-545. 
Pastor, J., B. Dewey, R. J. Naiman, P. F. McInnes, and Y. Cohen. 1993. Moose browsing and soil fertility in the boreal forests of Isle Royale National Park. Ecology 74:467-480.

Pitt, M.D. and F.E. Schwab. 1990. Assessment of a nondestructive method for estimating browse use. Journal of Wildlife Management 54(1):175-179.

Rummell, R. S. 1951. Some effects of grazing on ponderosa pine forest and range in central Washington. Ecology 32:594-607.

Shannon, C.E., and W. Weaver 1962. The mathematical theory of communication. University of Illinois Press, Urbana.

Singer, F. J., L. Mack, and R. G. Cates. 1994. Ungulate herbivory of willows on Yellowstone's northern winter range. Journal of Range Management 47:435-443.

Smith, B.L., and R.L. Robbins. 1994. Migrations and management of the Jackson elk herd. National Biological Survey Research Publications No. 1999. National Biological Survey, Washington, D.C.

Smith, S., S. Kilpatrick, A. Reese, B. Smith, T. Lemke and D. Hunter. 1994. Wildlife habitat, feedgrounds and brucellosis in the Greater Yellowstone area. Paper presented at the National Brucellosis Symposium, Jackson, WY. September 1994.

Stohlgren, T.J., B.M. Falkner, and L.D. Schell. 1995. A Modified-Whittaker nested vegetation sampling method. Vegetatio 117:113-121.

Stohlgren, T.J., G.W. Chong, M.A. Kalkhan, and L.D. Schell. 1997. Rapid assessment of plant diversity patterns: A methodology for landscapes. Environmental Monitoring and Assessment 48:25-43.

Stohlgren, T. J., L. D. Schell, and B. V. Heuvel. 1999. How grazing and soil quality affect native and exotic plant diversity in Rocky Mountain Grasslands. Ecological Applications 9:45-64.
SysStat ${ }^{\circledR} .1996$. Version 6.0 , SPSS, Chicago, Illinois, USA.

Thorne, E.T., J.D. Herriges and A.D. Reese. 1991. Bovine brucellosis in elk: conflicts in the Greater Yellowstone Area. Pages 296-303 in A.G. Christensen, L.J. Lyon and T.N. Lonner, comps., Proc. Elk Vulnerability Symp., Montana State Univ. Bozeman.

Van Manen, F.T., and M.R. Pelton. 1997. A GIS model to predict black bear habitat use. Journal of Forestry 95:6-12.

Wagner, F. H., R. Foresta, R. B. Gill, D. R. McCullough, M. R. Pelton, W. F. Porter, and H. Salwasser. 1995a. Wildlife policies in the U.S. National Parks. Island Press, Washington, D.C.

Webber, W.A. 1976. Rocky Mountain Flora. University Press of Colorado, Colorado.

Table 1. Sample size of observed and random animal locations used for habitat selection model testing for elk, bison, and moose in the Jackson Valley/Greater Teton area of Wyoming.

\begin{tabular}{|l|l|l|}
\hline & $\begin{array}{l}\text { Actual animal } \\
\text { observations }\end{array}$ & $\begin{array}{l}\text { Random } \\
\text { locations }\end{array}$ \\
\hline $\begin{array}{l}\text { Actual animal } \\
\text { observations }\end{array}$ & $\begin{array}{l}\text { Random } \\
\text { locations }\end{array}$ \\
\hline $\begin{array}{l}\text { Elk early } \\
\text { winter }\end{array}$ & 479 & 660 \\
\hline $\begin{array}{l}\text { Elk late } \\
\text { winter }\end{array}$ & 819 & 884 \\
\hline $\begin{array}{l}\text { Bison early } \\
\text { winter }\end{array}$ & 222 & 192 \\
\hline $\begin{array}{l}\text { Bison late } \\
\text { winter }\end{array}$ & 143 & 624 \\
\hline Moose & 624 & 624 \\
\hline
\end{tabular}




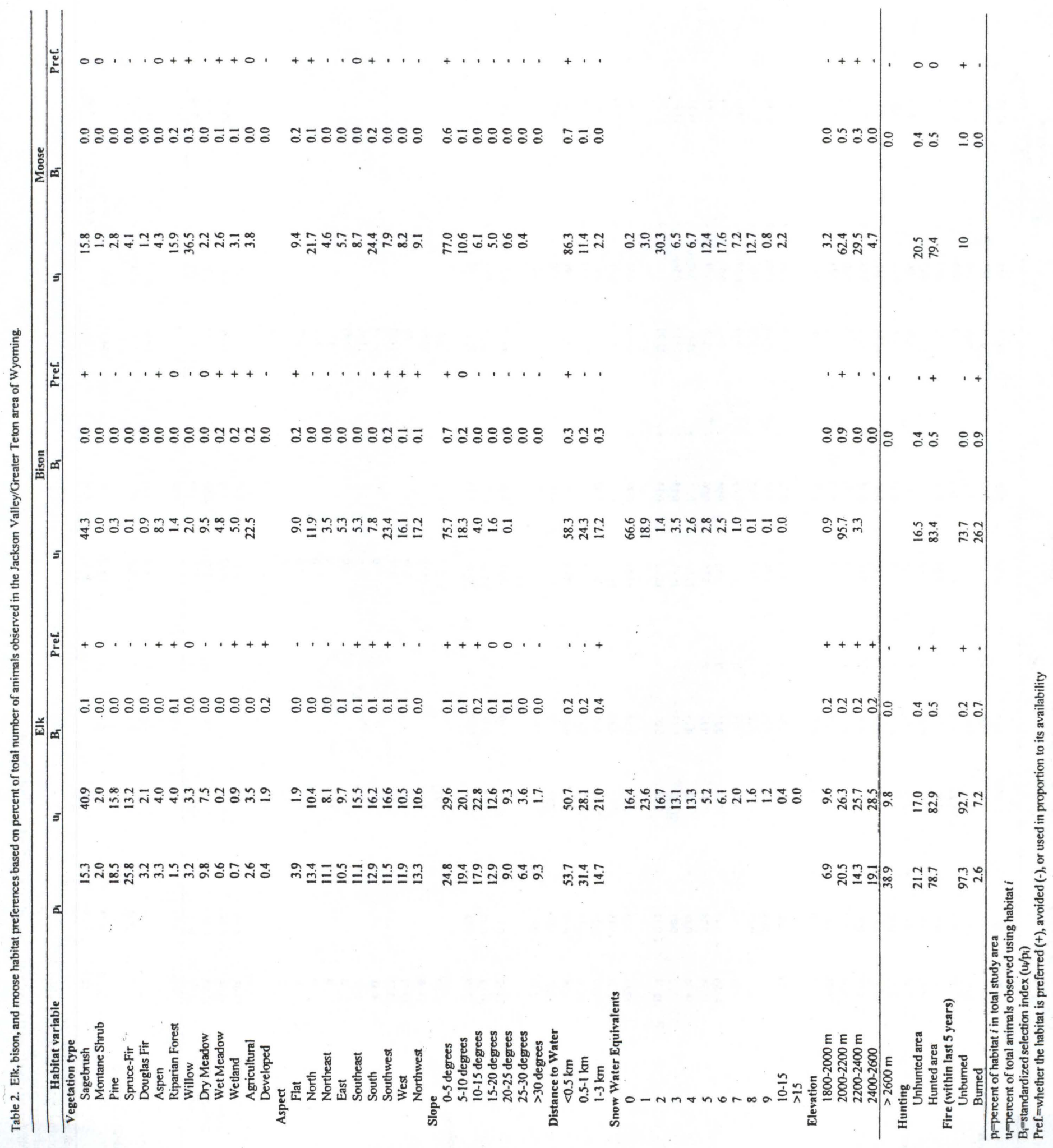




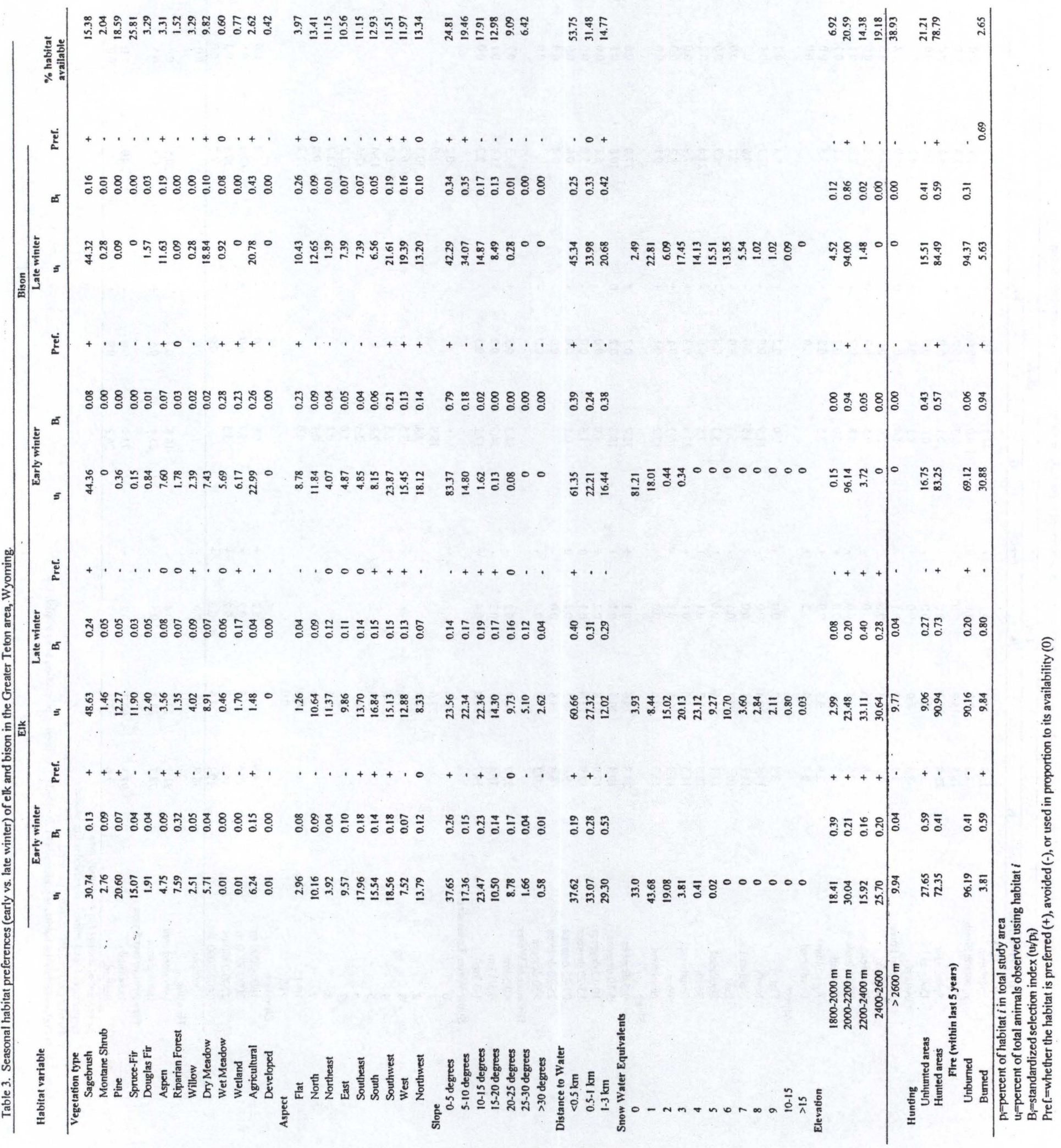


Table 4. Total numbers of animals observed during ungulate surveys in Grand Teton National Park, Wyoming during Summer 2000.

\begin{tabular}{llrrrrrr}
\hline Date & Time & Elk & Bison & Pronghorn & Mule Deer & Cattle & Horses \\
\hline $5 / 31 / 00$ & Evening & 89 & 4 & 2 & 0 & 0 & 0 \\
$6 / 1 / 00$ & Morning & 30 & 49 & 4 & 0 & 0 & $?$ \\
$6 / 1 / 00$ & Evening & 159 & 4 & 2 & 0 & 0 & 11 \\
$6 / 5 / 00$ & Evening & 133 & 68 & 6 & 0 & 0 & 17 \\
$6 / 6 / 00$ & Evening & 108 & 72 & 3 & 0 & 0 & 20 \\
$6 / 7 / 00$ & Morning & 125 & 74 & 7 & 0 & 0 & 43 \\
$6 / 18 / 00$ & Morning & 134 & 64 & 4 & 0 & 0 & 58 \\
$6 / 25 / 00$ & Evening & 125 & 21 & 18 & 0 & 0 & 5 \\
$6 / 26 / 00$ & Evening & 111 & 26 & 4 & 0 & 1000 & 36 \\
$6 / 28 / 00$ & Evening & 43 & 19 & 0 & 0 & 1000 & 18 \\
$6 / 29 / 00$ & Evening & 105 & 32 & 0 & 0 & 1000 & 39 \\
$7 / 13 / 00$ & Morning & 42 & 17 & 23 & 0 & 1000 & 60 \\
$7 / 19 / 00$ & Evening & 2 & 1 & 0 & 1 & 1000 & 29 \\
$8 / 3 / 00$ & Morning & 89 & 0 & 5 & 2 & 1068 & 21 \\
\hline
\end{tabular}

Table 5. Mean bison and elk numbers seen during ungulate surveys before and after arrival of cattle on grazing allotments in Grand Teton National Park, Wyoming, summer 2000.

\begin{tabular}{lcccc}
\hline & \multicolumn{2}{c}{ Bison } & & Elk \\
\cline { 2 - 5 } Grazing Allotment & Before cattle grazing & $\begin{array}{c}\text { After/during } \\
\text { cattle grazing }\end{array}$ & Before cattle grazing & $\begin{array}{c}\text { After/during } \\
\text { cattle grazing }\end{array}$ \\
\hline North East Elk Ranch & 0.67 & 0.00 & 8.42 & 0.00 \\
South East Elk Ranch & 3.64 & 0.67 & 15.27 & 0.67 \\
Lower Cunningham & 2.38 & 0.00 & 16.00 & 1.33 \\
Uhl Hill & 11.85 & 0.00 & 9.85 & 0.00 \\
West Elk Ranch & 15.13 & 2.17 & 26.63 & 14.50 \\
\hline
\end{tabular}

Table 6. Average species cover for grazed and ungrazed plots in the Jackson Valley, Wyoming.

\begin{tabular}{|c|c|c|c|}
\hline \multicolumn{2}{|c|}{ Grazed } & \multicolumn{2}{|c|}{ Ungrazed } \\
\hline Species & $\%$ Cover & Species & $\%$ Cover \\
\hline Artemisia tridentata & 8.6 & Agropyron spicatum & 12.6 \\
\hline Agropyron spicatum & 7.0 & Purshia tridentata & 8.5 \\
\hline Antennaria rosea & 6.5 & Poa fendleriana & 8.2 \\
\hline Phlox muscoides & 6.4 & Artemisia tridentata & 7.3 \\
\hline Poa pratensis & 6.2 & Antennaria rosea & 6.1 \\
\hline Poa fendleriana & 5.8 & Poa pratensis & 5.2 \\
\hline Amelanchier alnifolia & 4.0 & Phlox muscoides & 4.9 \\
\hline Agropyron smithii & 3.3 & Amelanchier alnifolia & 2.9 \\
\hline Solidago species 1 & 3.1 & Koeleria macrantha & 2.7 \\
\hline
\end{tabular}



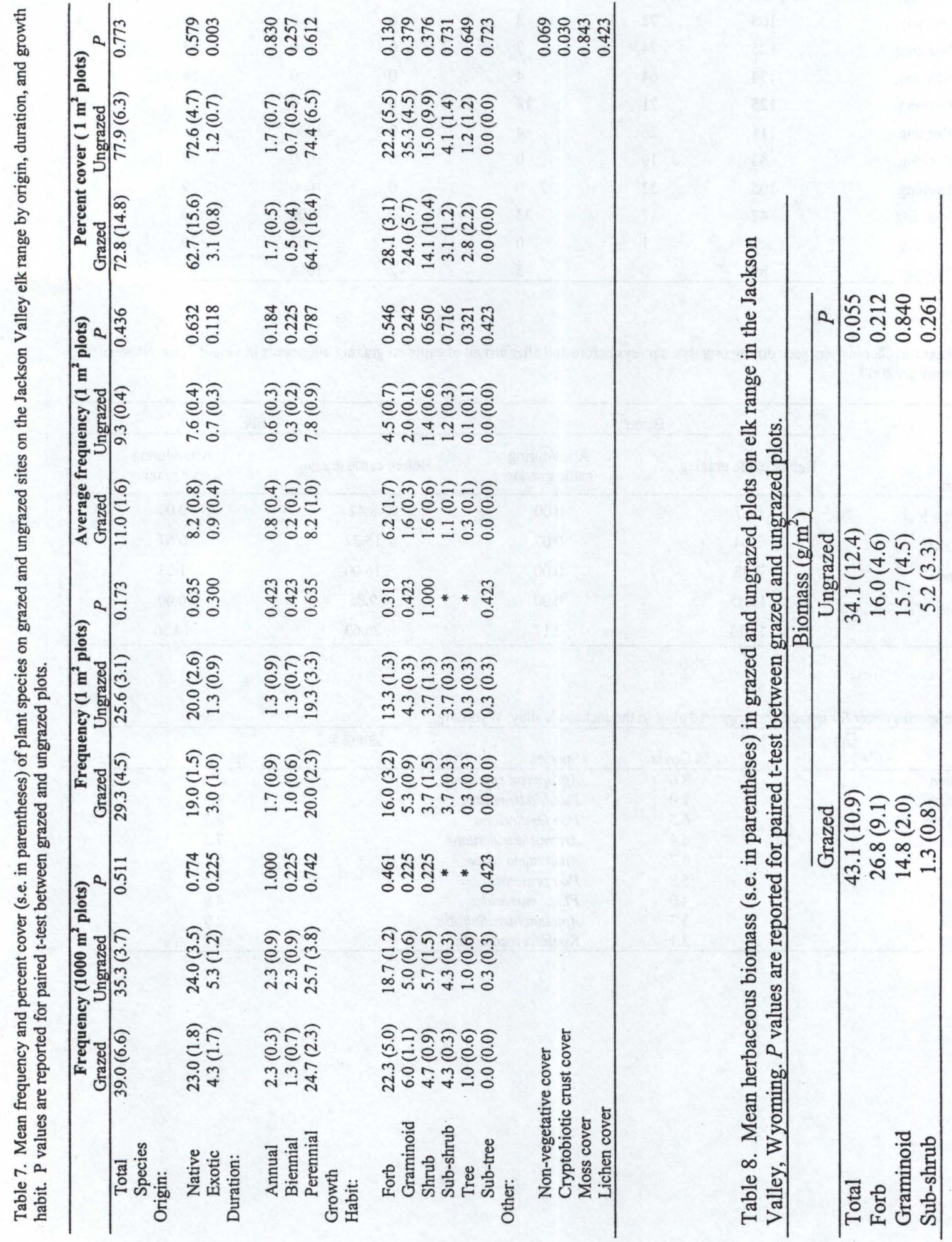


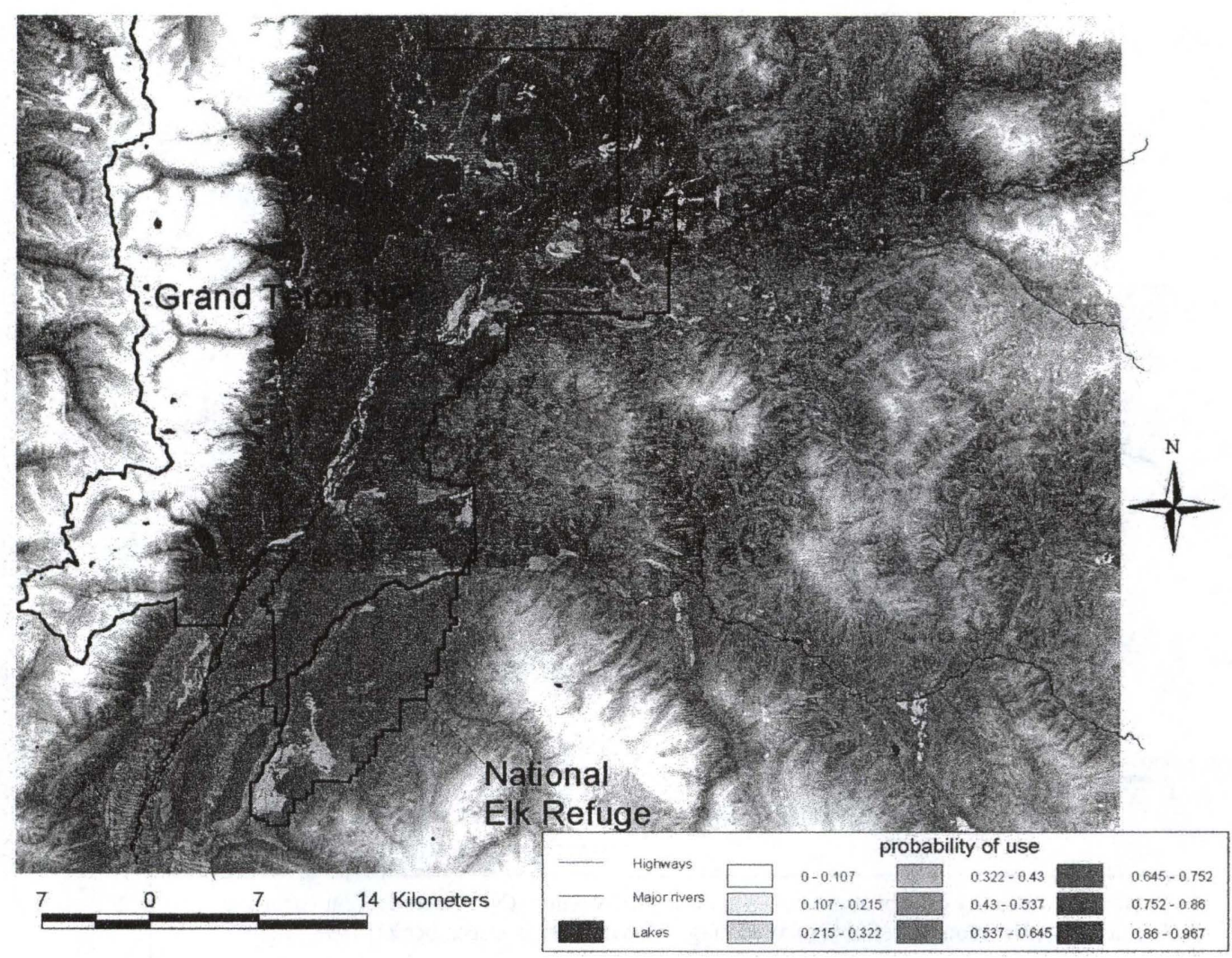

Figure 1. Probability of habitat use by elk during early winter (Nov-Dec). in the Greater Teton/Jackson Valley area of Wyoming. Modeled day is December 21, 1998.

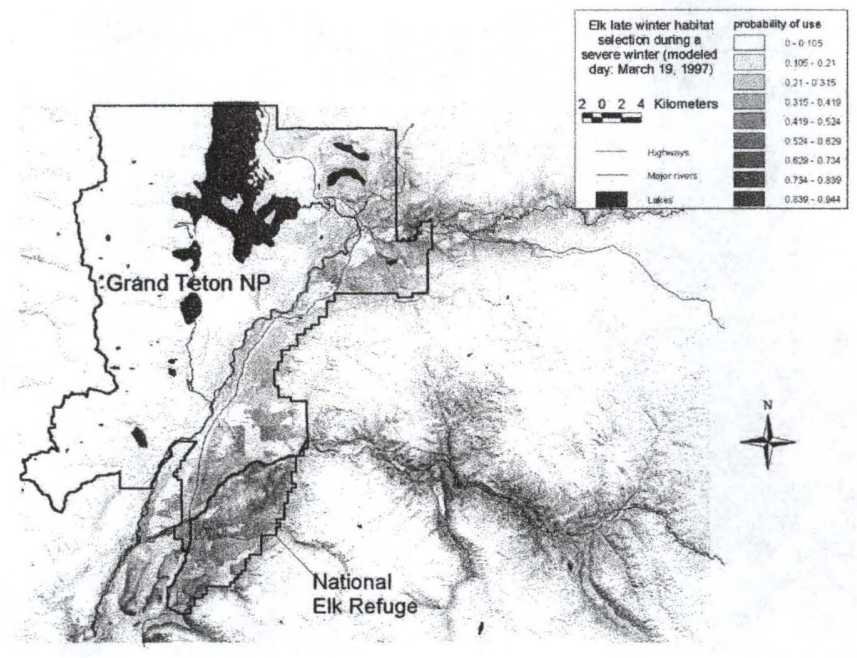

Figure 2. Probability of habitat use by elk during late winter (JanuaryApril) in the Greater Teton/Jackson Valley area of Wyoming. Modeled day is March 19, 1997--a severe winter. 


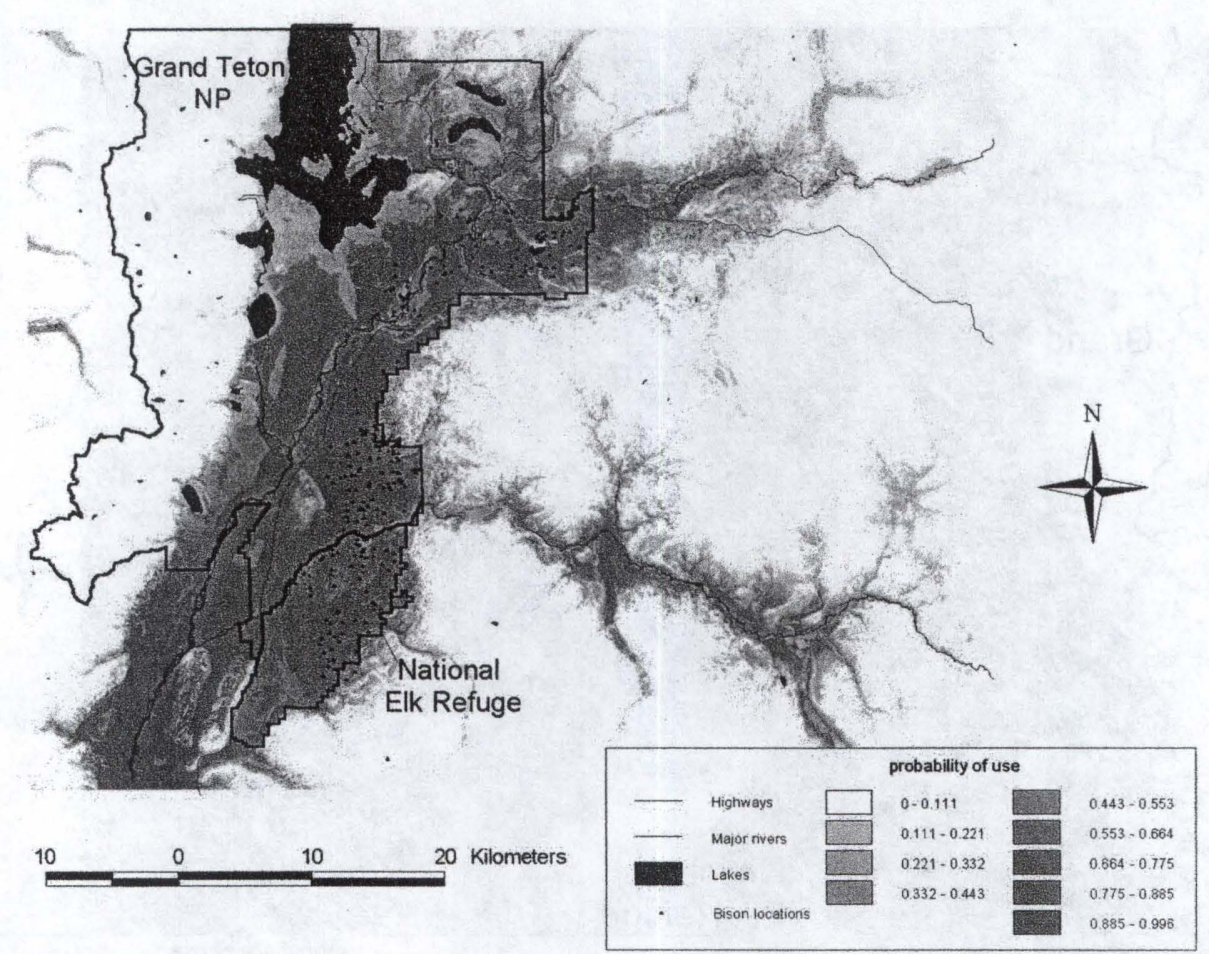

Figure 3. Probability of habitat use by bison during early winter (November-December) in the Greater Teton/Jackson Valley area of Wyoming. Modeled day is December 21, 1998.

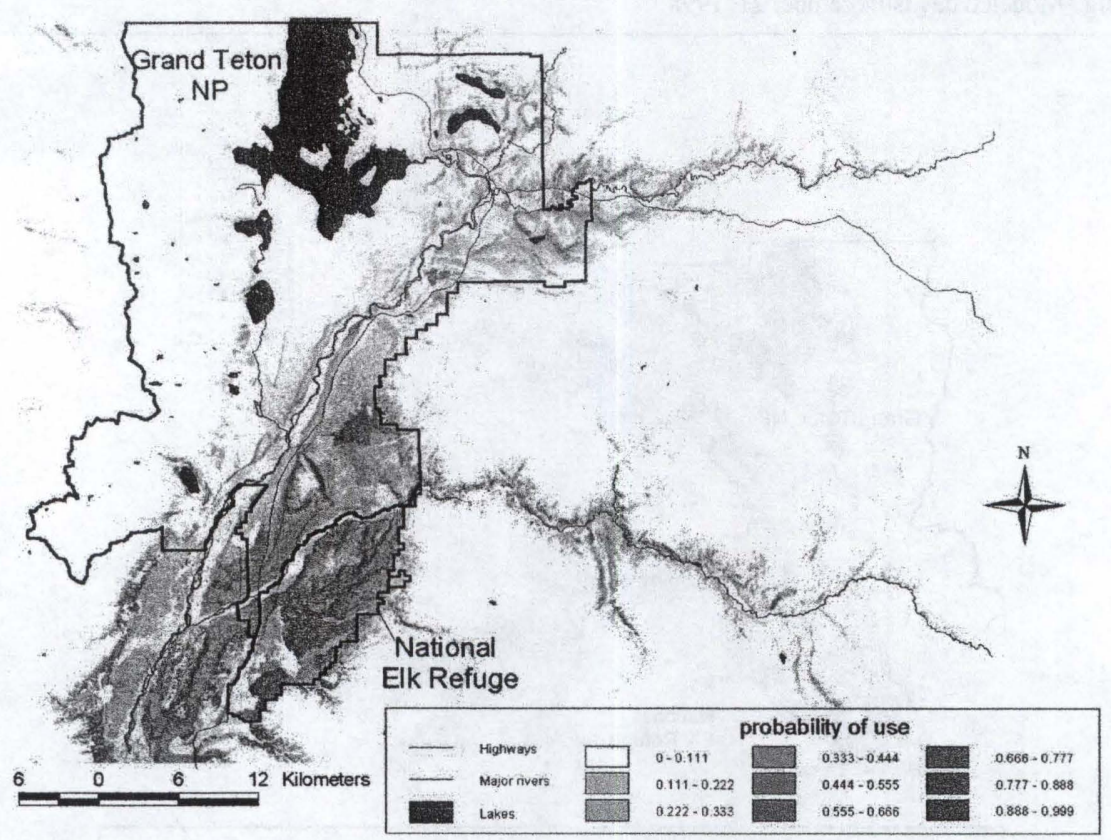

Figure 4. Probability of habitat use by bison during late winter (January-April) in the Greater Teton/Jackson Valley area of Wyoming. Modeled day is March 19, 1997--a severe winter. 


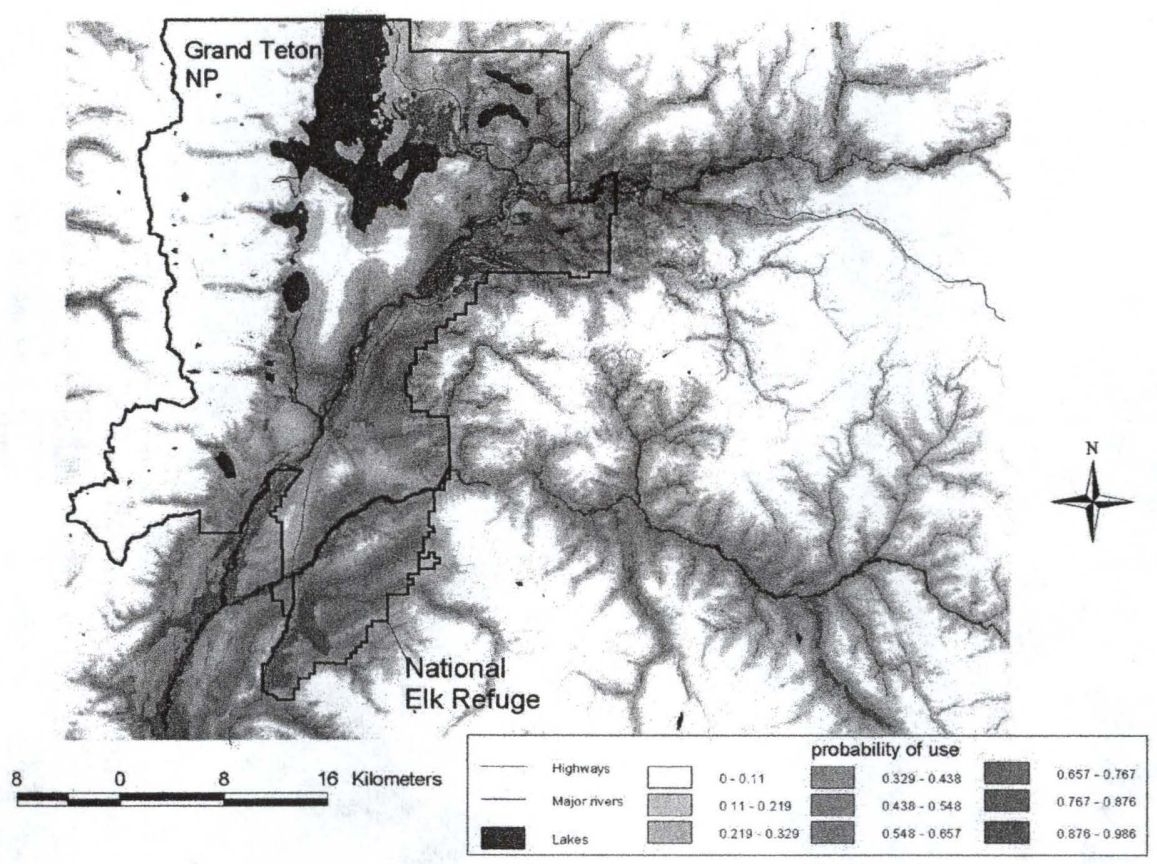

Figure 5. Probability of habitat use by moose during a mild winter in the Greater Teton/Jackson Valley area of Wyoming. Modeled day is February 14, 1995.

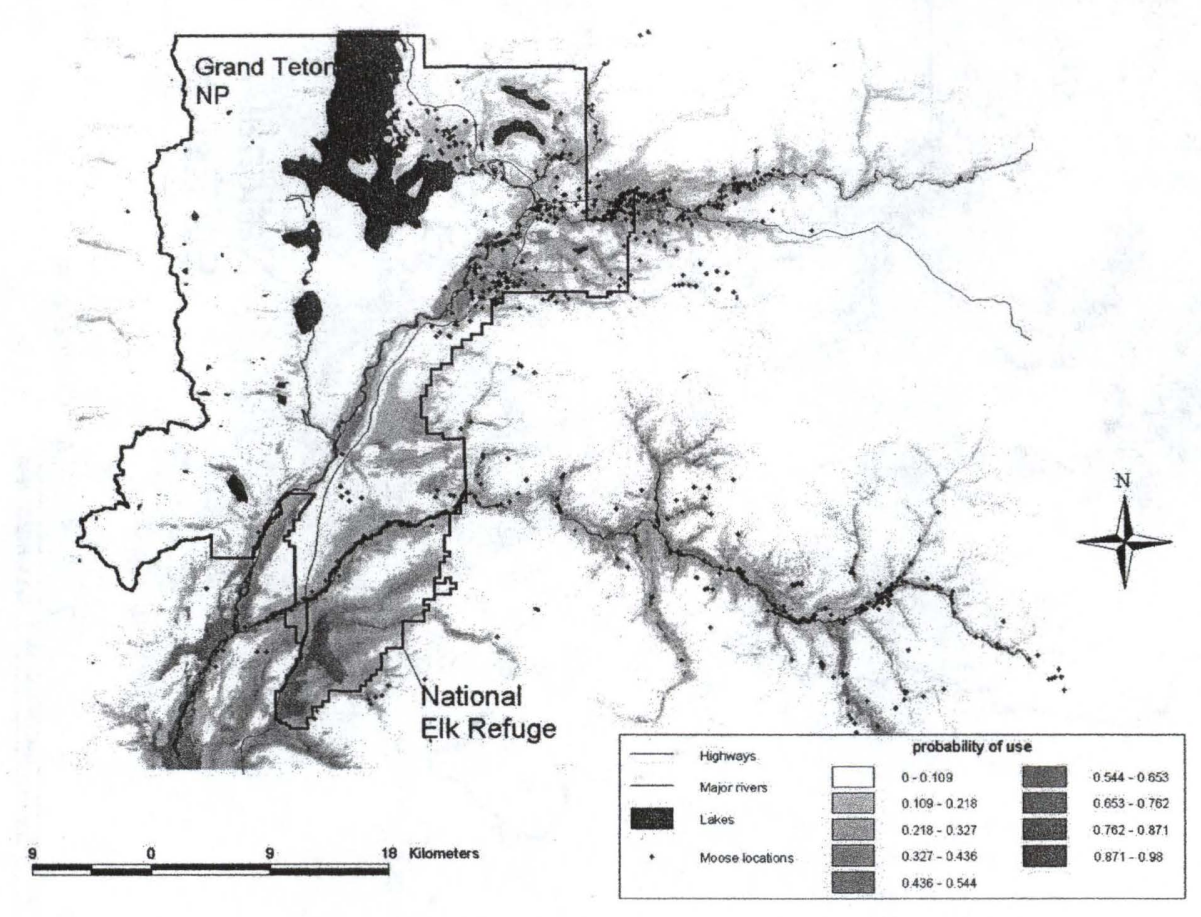

Figure 6. Probability of habitat use by moose during a severe winter in the Greater Teton/Jackson Valley area of Wyoming. Modeled day is March 19, 1997. 


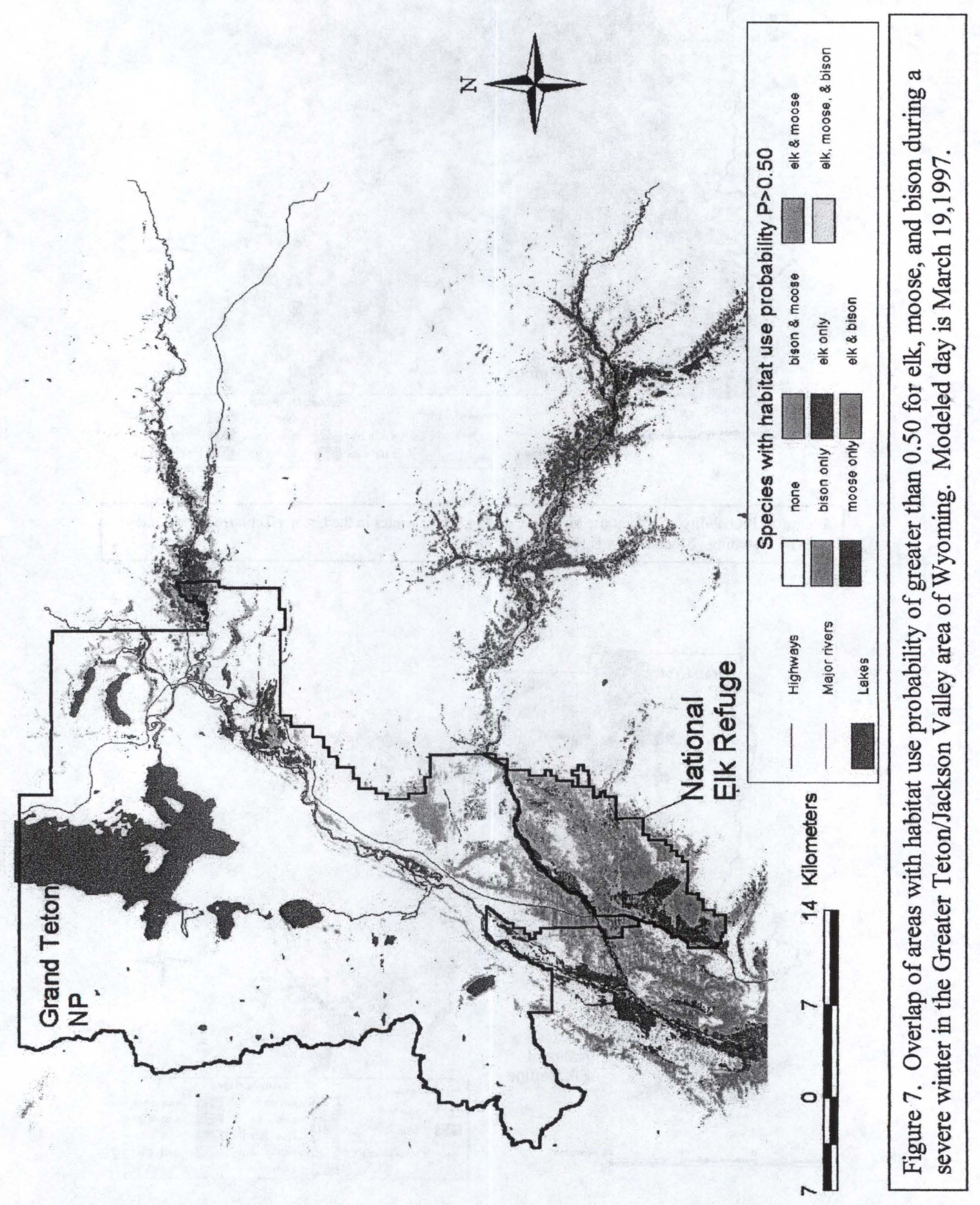


a)

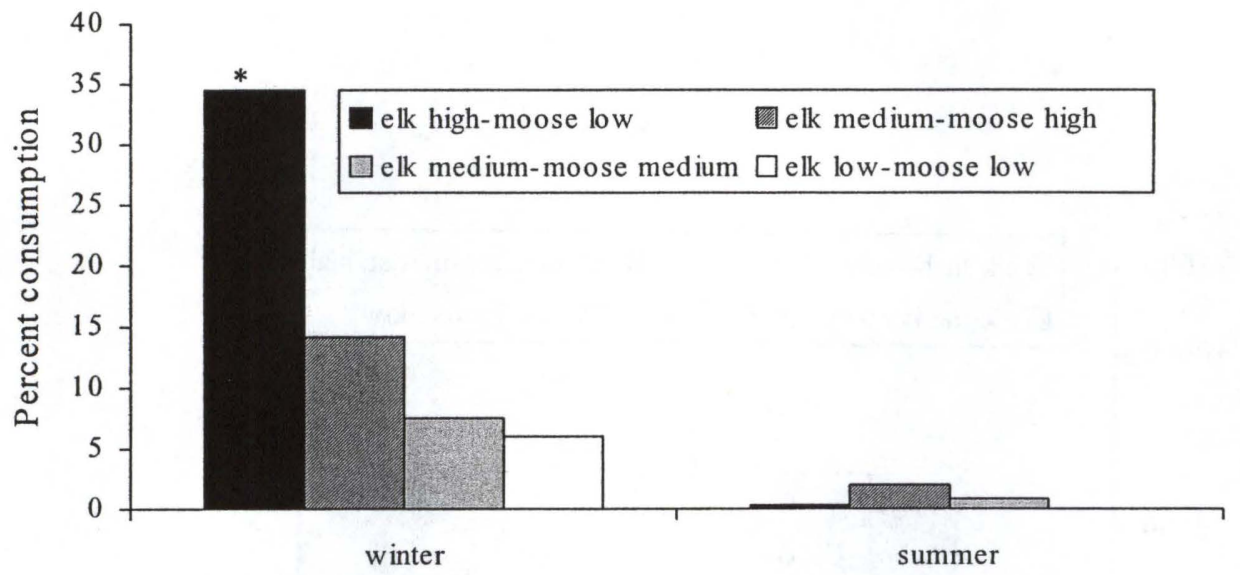

b)

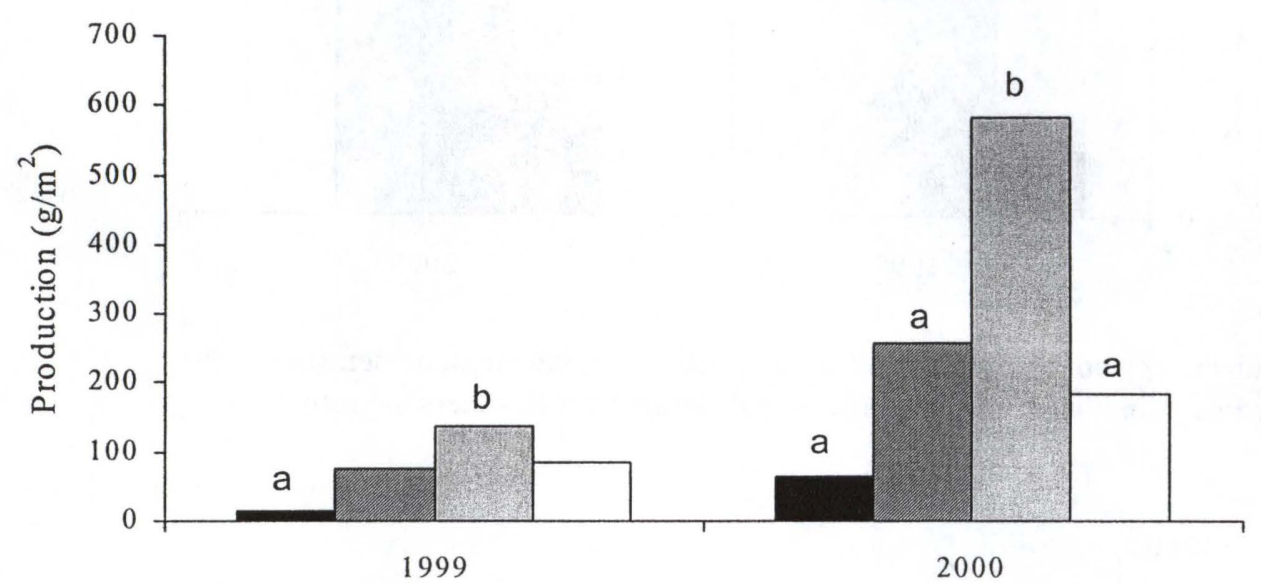

c)

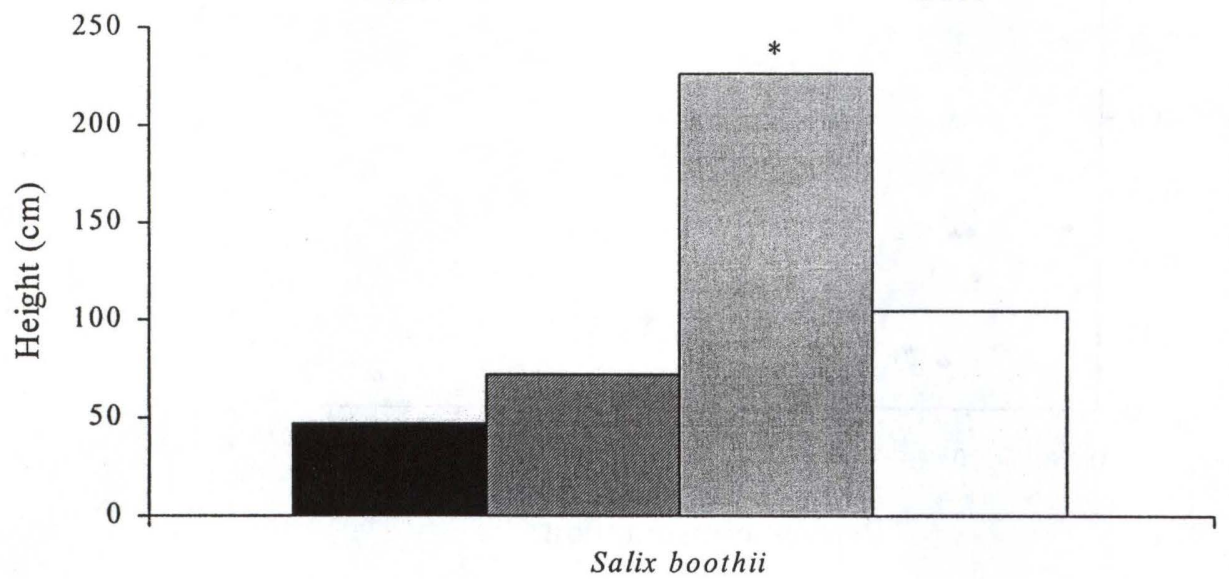

Figure 8. Percent consumption (a), production (b), and heights (c) of willows compared between differing ungulate density strata for elk and moose in the Greater Teton area. * indicates value significantly different than all others in group $(\mathrm{P} \leq 0.10)$. Different letters denote significant differences between categories $(\mathrm{P} \leq 0.10)$. 


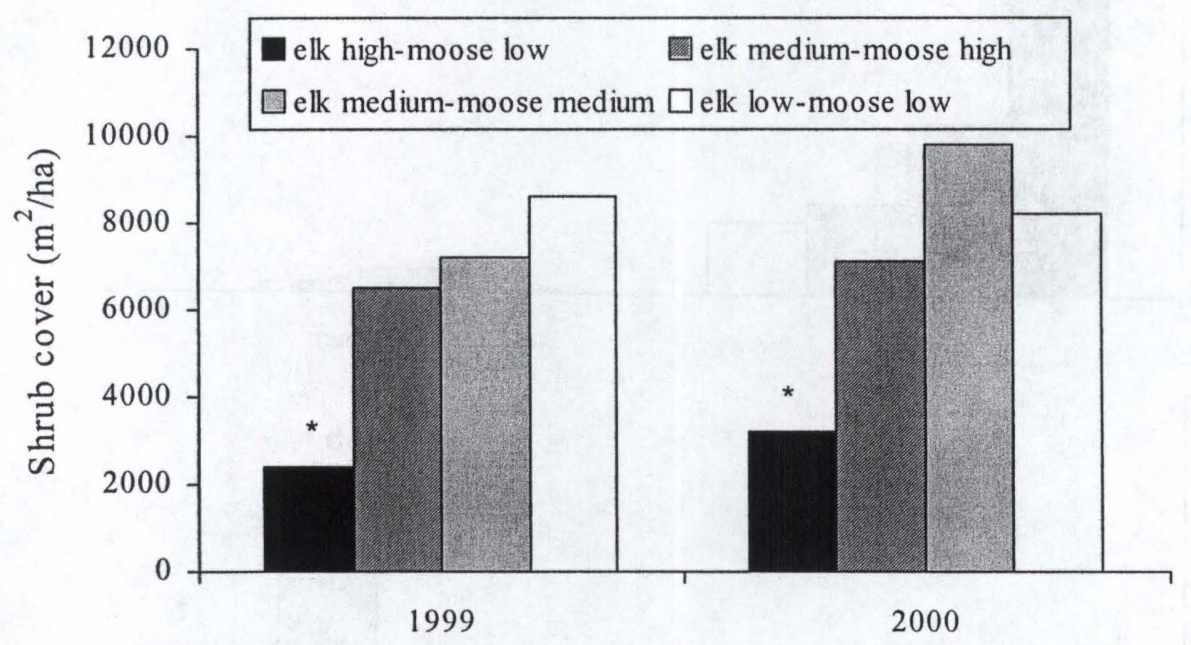

Figure 9. Shrub canopy cover in willow sites subjected to varying ungulate densities in the Greater Teton area. * indicates mean significantly different than all others in group $(\mathrm{P} \leq 0.10)$

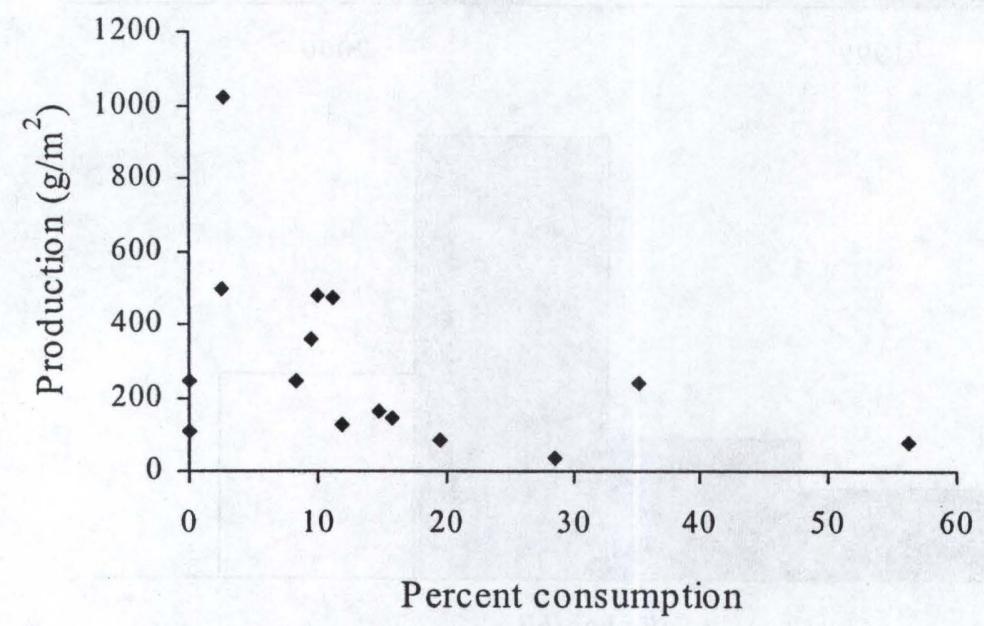

Figure 10. Relationship between shrub annual production and percent consumption in the Greater Teton area. 

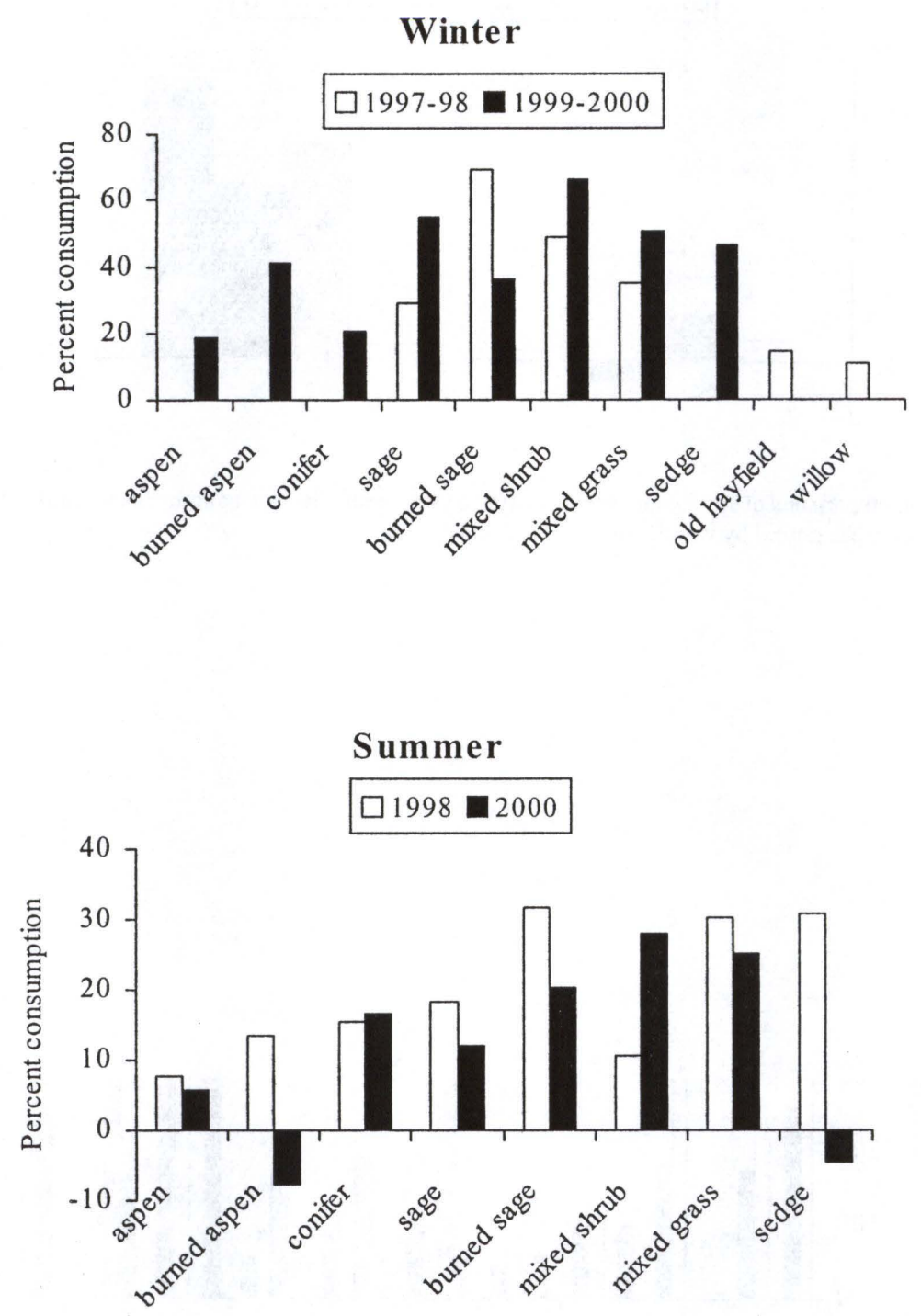

Figure 11. Winter and summer consumption rates in different vegetation types on elk and bison winter range in the Greater Teton area. 


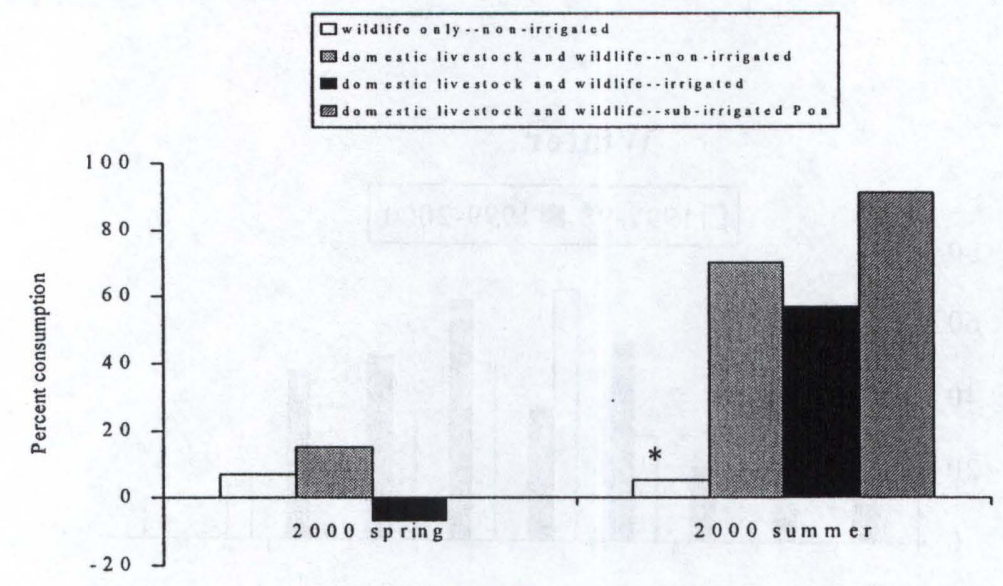

Figure 12. Comparisons of spring and summer offtake in domestic livestock allotments (wildlife plus livestock) vs. areas grazed by wildlife only in the Greater Teton Area.

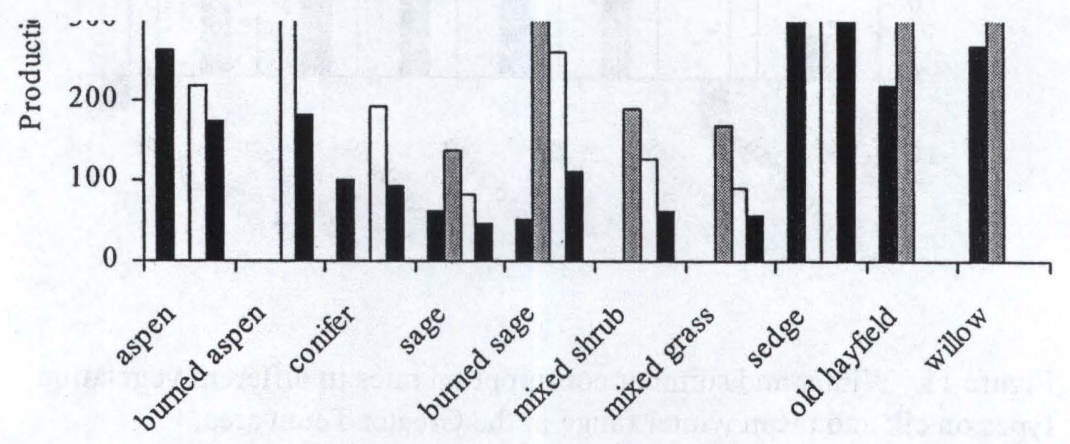

Figure 13. Annual herbaceous biomass production in elk and bison winter range habitats, $1996-2000$ in the Greater Teton Area. 


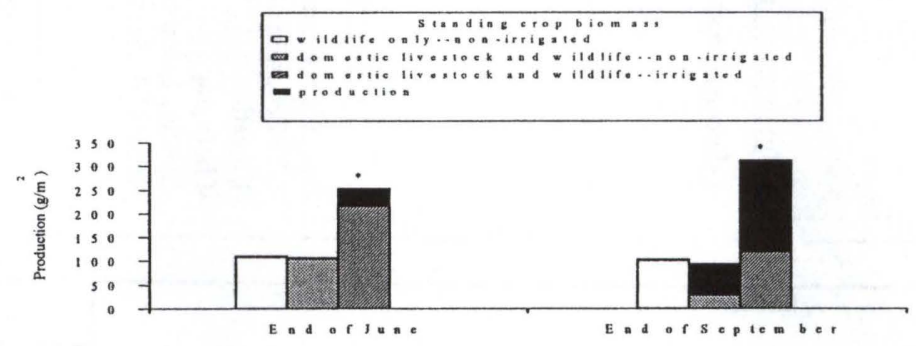

Figure 14. Differences in herbaceous standing crop biomass and production between irrigated and non-irrigated pastures which are grazed by wildlife and livestock in Grand Teton National Park, 2000.

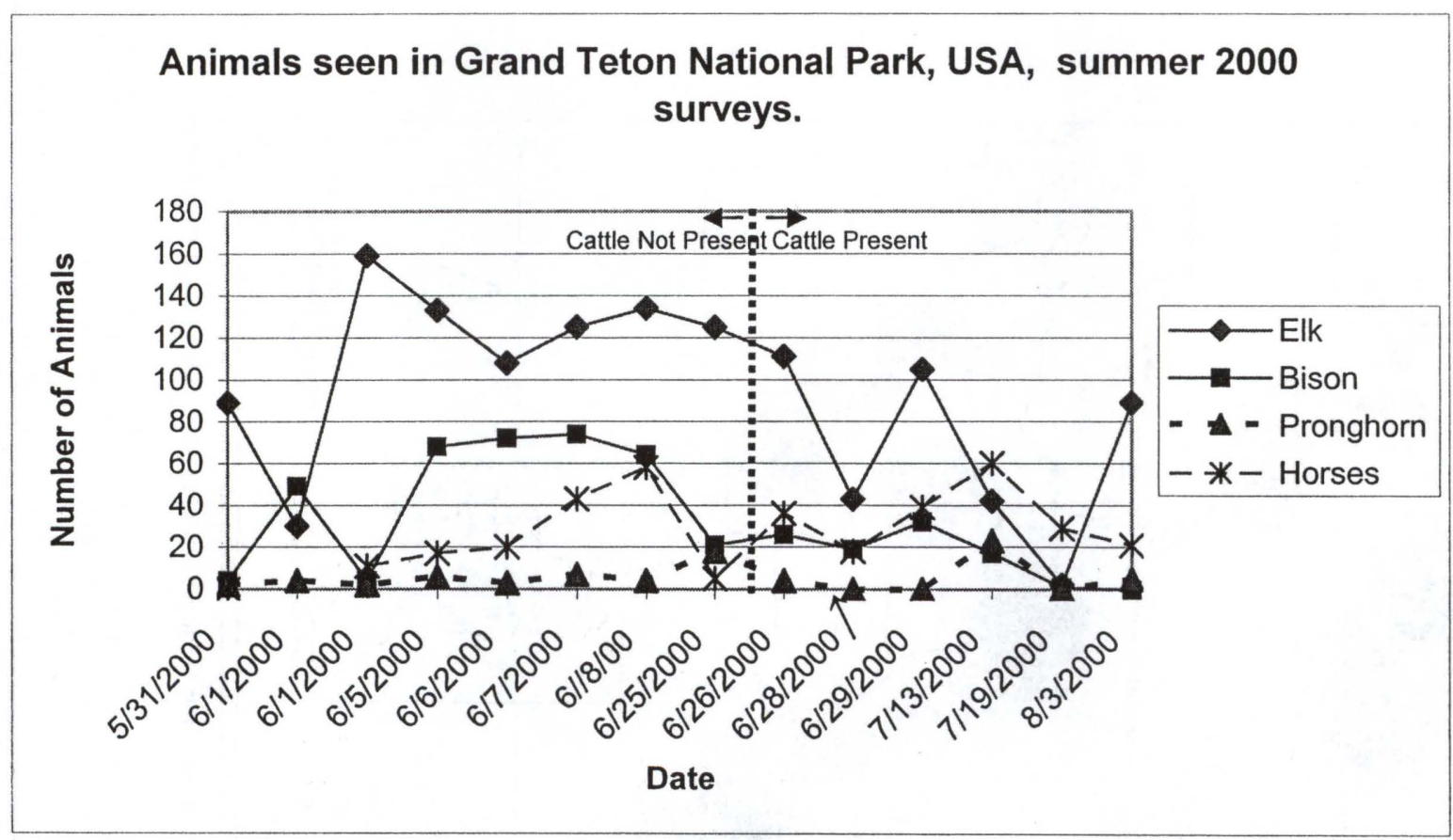

Figure 15. Ungulates seen during wildlife observation surveys in Grand Teton National Park, summer 2000 (excluding cattle). 

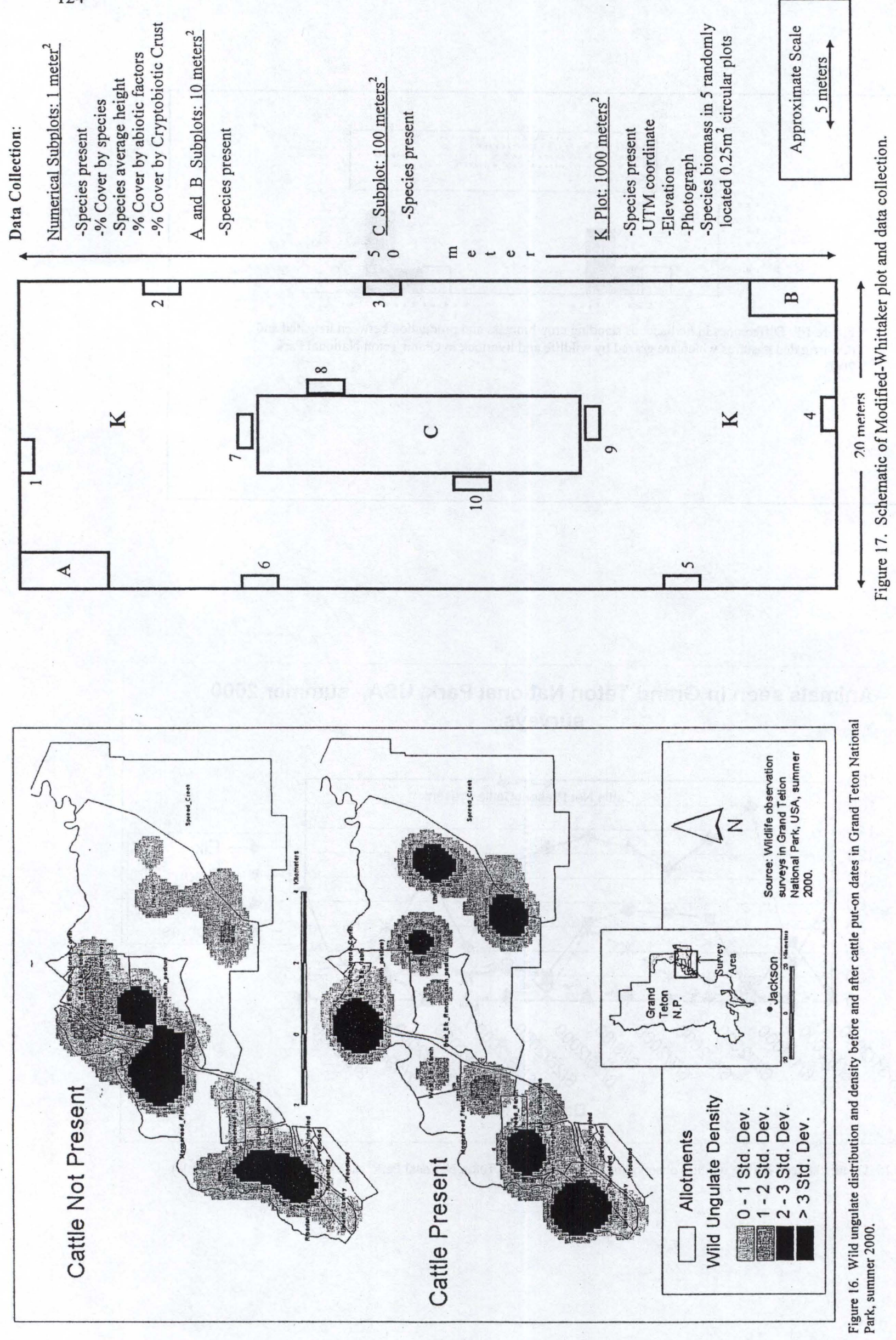